\title{
THESIS
}

\section{MERGING YOGA AND OCCUPATIONAL THERAPY FOR PARKINSON'S DISEASE IMPROVES FATIGUE MANAGEMENT AND ACTIVITY AND PARTICIPATION MEASURES}

\author{
Submitted by \\ Heather M. Hill \\ Department of Occupational Therapy \\ In partial fulfillment of the requirements \\ For the Degree of Master of Science \\ Colorado State University \\ Fort Collins, Colorado
}

Summer 2019

Master's Committee:

Advisor: Arlene A. Schmid

Karen E. Atler

Brett W. Fling 
Copyright by Heather M. Hill 2019

All Rights Reserved 


\begin{abstract}
MERGING YOGA AND OCCUPATIONAL THERAPY FOR PARKINSON'S DISEASE IMPROVES FATIGUE MANAGEMENT AND ACTIVITY AND PARTICIPATION MEASURES
\end{abstract}

Introduction: The purpose of this pilot study was to explore the influence of a fall-risk management intervention, Merging Yoga and Occupational Therapy for Parkinson's Disease (MY-OT-PD), on fatigue and activity and participation measures, as well as examine the relationship between fatigue and activity and participation measures in Parkinson's disease (PD).

Methods: This mixed methods study included 17 participants with PD. Participants took the Modified Fatigue Impact Scale (MFIS) and the International Classification of Functioning, Disability, and Health Measure of Participation and Activities Screener (IMPACT-S) at three separate eight-week intervals: baseline (followed by an eight-week control period), preintervention, and post-intervention. Focus groups were completed at the conclusion of the study to qualitatively explore participants' perception of the intervention related to their fatigue and activity and participation levels.

Results: Fatigue and activity and participation measures were significantly correlated $(r=0.76)$. Activity and participation measures (IMPACT-S) significantly improved after the intervention ( $p$ $=0.012$ ). Four themes related to fatigue and/or activity and participation emerged following qualitative analysis including: 1) managing fatigue: paying attention and acting accordingly; 2) 
creating mindfulness in daily activities; 3 ) giving and receiving within a community; and 4) strengthening relationship to self and others.

Conclusion: Participants experienced improvement in activity and participation measures as well as perceived fatigue management after engagement in a community-based, fall-risk management program, MY-OT-PD. 


\section{ACKNOWLEDGEMENTS}

I would like to acknowledge and thank my research team, who have made this research experience possible. Special thanks goes to my advisor, Dr. Arlene Schmid, for her intuitive guidance, support, comradery, and optimism. I thank her for her confidence in me and her ability to find success at every stage of the thesis process. To Dr. Karen Atler, for guiding me in the qualitative process and challenging me to expand my horizons. To Dr. Brett Fling, for providing a unique perspective, expertise, and encouragement. To my mentor, Laura Swink, for her development, dedication, and incredible knowledge of this project. To Abby Anderson, my yoga research companion, whose innate ability to genuinely celebrate in others success and ability to critically analyze information provided priceless support to me.

I would also like to thank my family and friends, who have continually lent a listening ear or helping hand throughout this process. My sincerest thanks to the participants of the intervention, who bravely and openly shared their experiences. A warm thank you to Jennifer Atkins, whose knowledge of yoga and ability to teach it are inspirational. Lastly, I would like to dedicate this thesis to the people in my life who have helped foster a love of yoga within me. 


\section{TABLE OF CONTENTS}

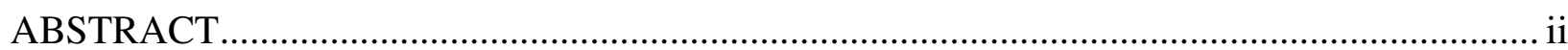

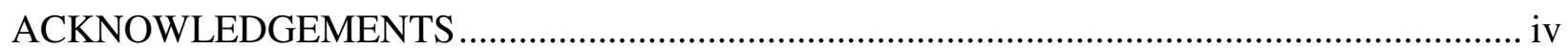

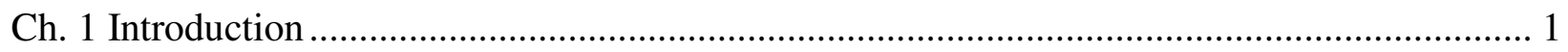

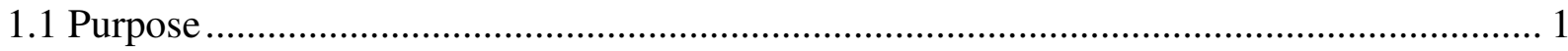

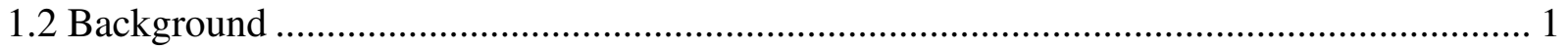

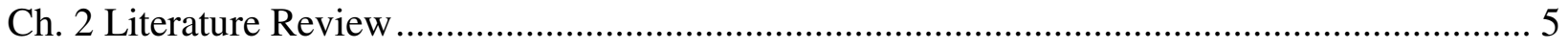

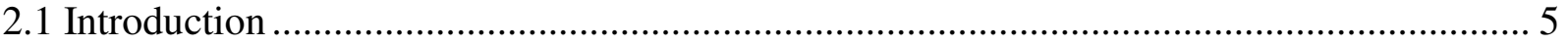

2.2 Overview of Parkinson's Disease ................................................................................. 5

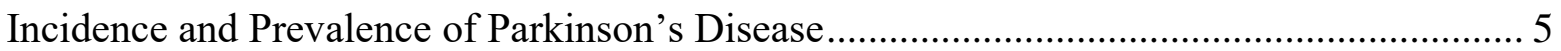

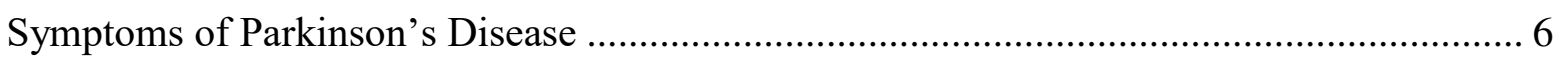

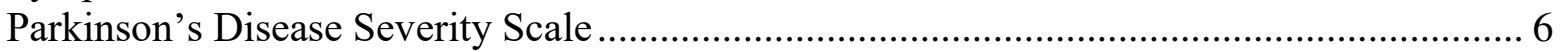

Treatment in Parkinson's Disease ………………........................................................... 7

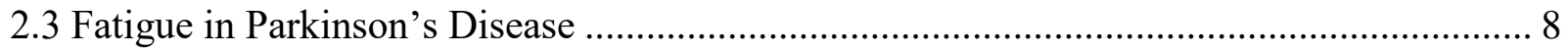

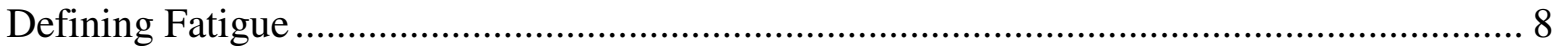

Incidence and Prevalence of Fatigue in Parkinson's Disease............................................... 9

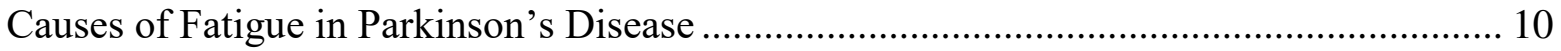

Treatment for Fatigue in Parkinson's Disease ................................................................... 11

2.3 Relationship Between Fatigue and Falling in Parkinson's Disease .................................. 11

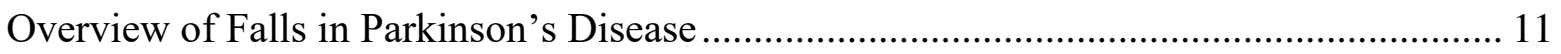

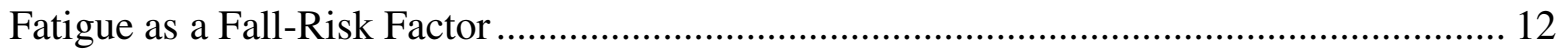

2.4 Relationship Between Falling and Activity and Participation in Parkinson's Disease ....... 13

2.5 Relationship Between Fatigue and Activity and Participation in Parkinson's Disease ...... 15

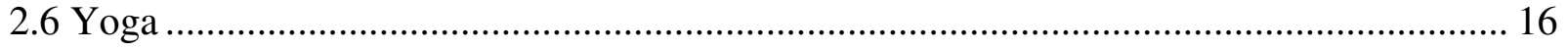

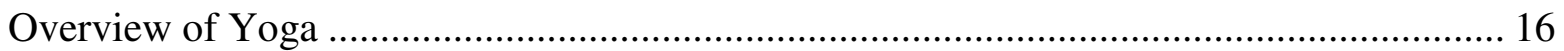

Yoga as an Intervention for Parkinson's Disease ................................................................ 17

Yoga as an Intervention for Fatigue .......................................................................... 19

2.7 Occupational Therapy Intervention for Parkinson's Disease............................................. 19

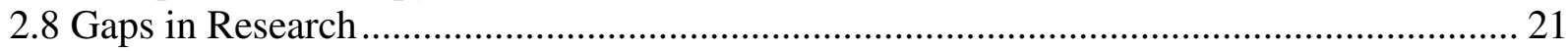

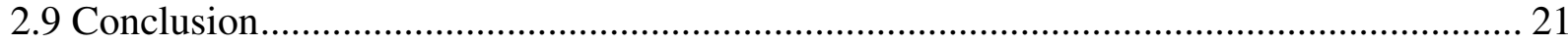

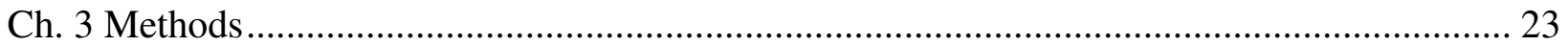

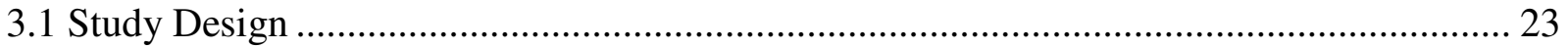

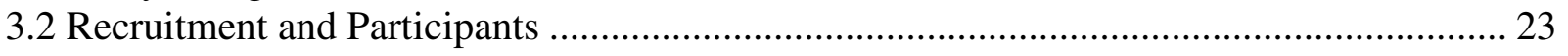

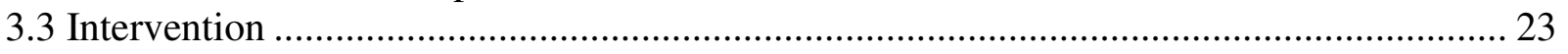

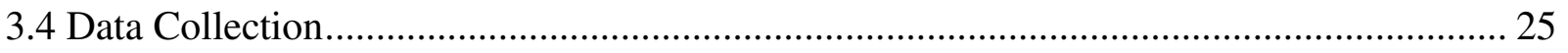

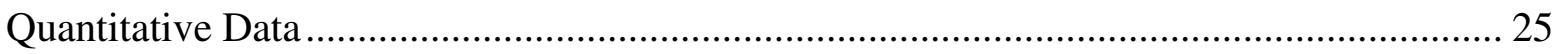

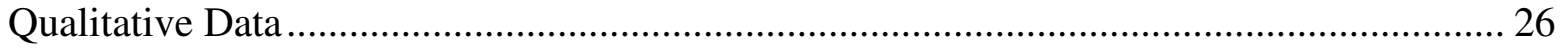

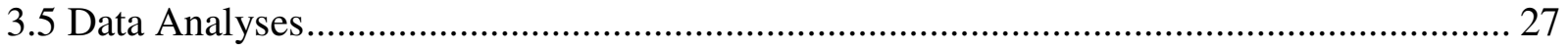




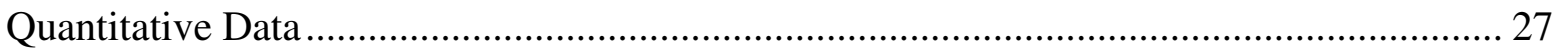

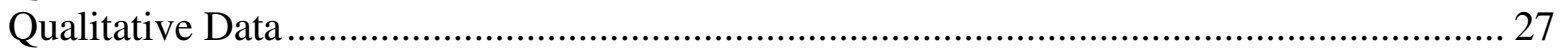

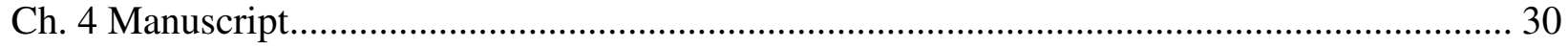

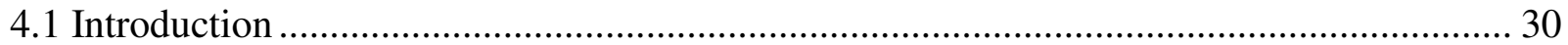

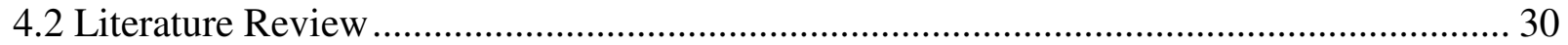

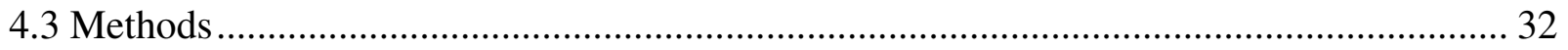

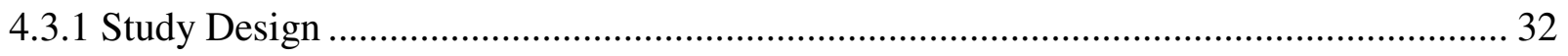

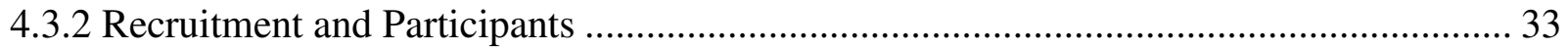

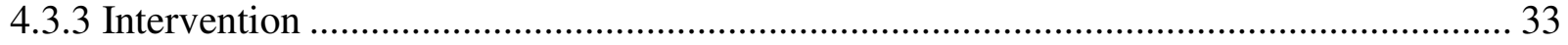

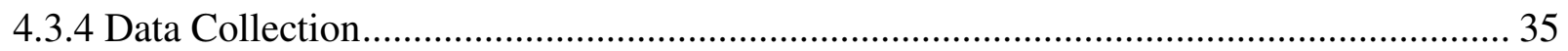

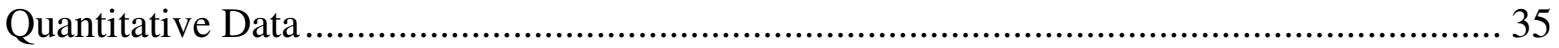

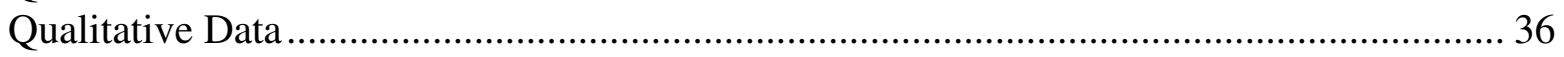

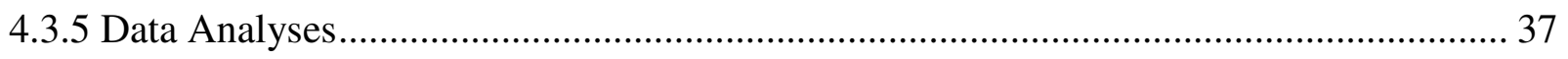

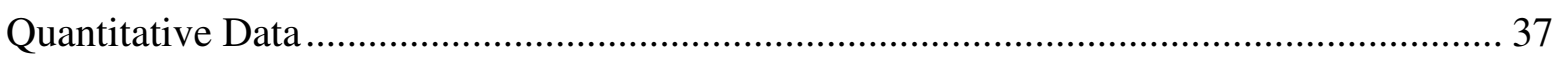

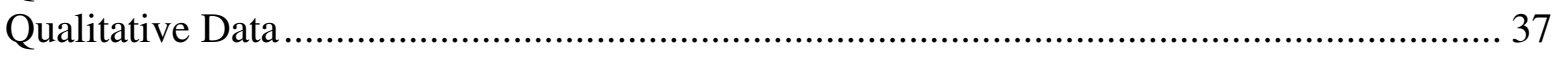

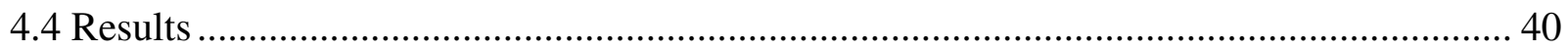

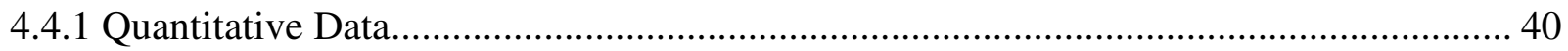

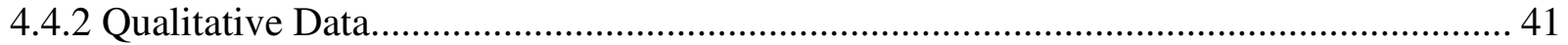

Theme 1: Managing Fatigue: "Paying Attention and Acting Accordingly" ...................... 41

Theme 2: Creating Mindfulness in Daily Activities.................................................. 43

Theme 3: Giving and Receiving Within a Community .............................................. 44

Theme 4: Strengthening Relationship to Self and Others ............................................ 46

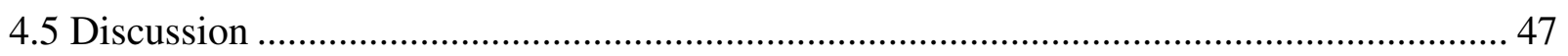

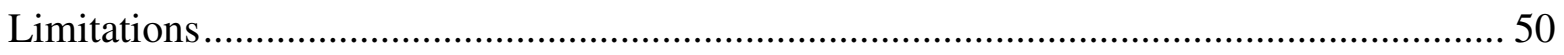

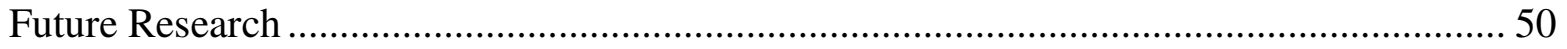

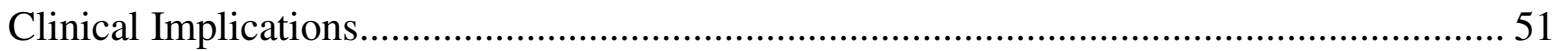

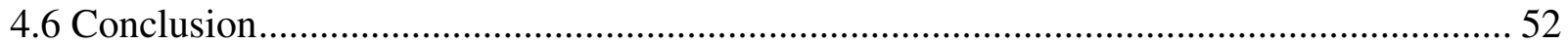

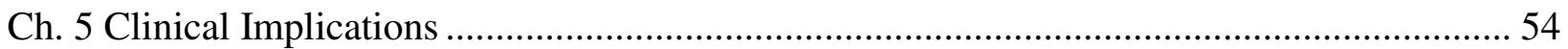

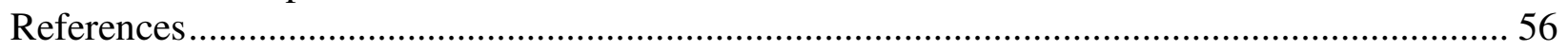




\section{Ch. 1 Introduction}

\subsection{Purpose}

The purpose of this study was to explore the influence of a fall-risk management program for people with Parkinson's disease (PD) on fatigue levels and activity and participation levels, as well as the relationship between fatigue and activity and participation in PD. The Merging Yoga and Occupational Therapy for PD (MY-OT-PD) program was an eight-week fall-risk management intervention that included group yoga and group occupational therapy (OT) sessions twice a week.

\subsection{Background}

PD is a progressive, chronic, neurodegenerative condition caused by the death of dopaminergic neurons in the basal ganglia (Bertram \& Tanzi, 2005; Lee \& Gilbert, 2016; Nassif \& Pereira, 2018). In the United States, about $1 \%$ of the population over 65 is diagnosed with PD, and that prevalence is expected to double by 2040 due to longer lifespan expectancies and the aging of the adult population (Nassif \& Pereira, 2018; Yan Yan Kwok, Cheuk Yin Kwan, Auyeung, Chung Tong Mok, \& Yue Lai Chan, 2017). PD is generally characterized by motor symptoms including rigidity, bradykinesia, tremor, and postural instability. The non-motor symptoms of the disease are often overlooked but can be just as disabling as the motor symptoms. The non-motor symptoms of PD include sleep disturbances, fatigue, depression, anxiety, autonomic dysfunction, dementia, and cognitive impairments (Bryant et al., 2012; Ongre, Larsen, Tysnes, \& Herlofson, 2017). Fatigue is one of the most common non-motor symptoms of PD (Nassif \& Pereira, 2018).

Fatigue in PD is multidimensional and can be related to a number of compounding factors including social and emotional disorders (Nassif \& Pereira, 2018; Nijrolder, van der 
Windt, \& van der Horst, 2008). Broadly, there are two types of fatigue in PD, objective and subjective. Objective fatigue is the physiological fatigue or fatigability that can be measured as physical performance declines. Subjective fatigue is composed of multiple facets including physical, social, emotional, and cognitive fatigue. Subjective fatigue occurs when one feels exhausted in any of these categories (Bryant et al., 2012; Nassif \& Pereira, 2018).

Because there are no biological markers for measuring subjective fatigue, it is often reported through self-report assessments (Siciliano et al., 2017). The percentage of people with PD who report subjective fatigue varies greatly- between 33-81\% (Kostić, Tomić, \& JečmenicaLukić, 2016). This broad range may be due to inconsistencies in definition and measurement tools. Fatigue is often described as one of the most upsetting symptoms related to PD, with "up to $1 / 3$ of PD patients report[ing] fatigue as their most disabling symptom" (Nassif \& Pereira, 2018, p.144).

Fatigue, falls, and activity and participation are connected in PD. For example, fatigue is a documented fall-risk factor. Bryant et al. (2012) found fatigue in PD to be present more significantly in people who had fallen when compared to non-fallers. Furthermore, people with PD are 2.7 times more likely to experience falls than age-matched peers, which is due to both the motor and non-motor symptoms of the disease, including fatigue (Bryant et al., 2012; Kader, Iwarsson, Odin, \& Nilsson, 2016; Pickering et al., 2007). In a recent study, 70\% of people with PD experienced a fall within one year (Van Puymbroeck et al., 2018). When people with PD experience a fall, it can lead to injury, fear of falling, and reduced activity and participation (Wood, Bilclough, Bowron, Walker, \& Psychiatry, 2002). Bryant and colleagues (2015) demonstrated that falls and fear of falling were significantly associated with activity of daily living (ADL) limitations and physical inactivity in people with PD. Furthermore, $41 \%$ of people 
with PD who had experienced a fall described reduced activity and participation after the fall (M. S. Bryant et al., 2015; Kader et al., 2016). These studies demonstrate that falling is an important concern for people with PD because falling may negatively impact the person's activity and participation levels.

Activity and participation, defined by the International Classification of Functioning, Disability, and Health (ICF), is composed of nine domains including: 1) learning and applying knowledge; 2) general tasks and demands; 3) communication; 4) mobility; 5) self-care; 6) domestic life; 7) interpersonal interactions and relationships; 8) major life areas; and 9) community, social and civic life (WHO, 2002). The relationship between fatigue and activity and participation in PD is not fully understood as both constructs are complex and dynamic. Several studies have shown negative correlations between fatigue and physical activity (Garber \& Friedman, 2003; Müller, Assmus, Herlofson, Larsen, \& Tysnes, 2013). McAuliffe, Baylor, and Yorkston (2017) studied communicative participation in PD, defined as "taking part in life situations where knowledge, information, ideas or feelings are exchanged"' (p.407), and found a negative association between fatigue and communicative participation. Because activity and participation cover a broad scope of domains, more research is needed to better understand the relationship with fatigue in PD.

Treatment in PD consists of pharmacological and non-pharmacological options. Many pharmacological treatment options come with negative side effects and poorly manage the nonmotor symptoms of PD (Davie, 2008). Yoga, as a non-pharmacological intervention for PD, has been shown to be beneficial for both motor and non-motor symptoms of the disease (Yan Yan Kwok et al., 2017). According to Sharma, Robbins, Wagner, and Colgrove (2015), people with PD who participated in yoga reported increased energy and relaxation, reduced fatigue, improved 
mood, positive social relationships, visible reduction in tremor, and attending to body signals more efficiently. Occupational therapy (OT) is a non-pharmacological treatment option that is beneficial for people with PD because OT supports and promotes a person's ability to engage in desired roles (Dixon et al., 2007; Sturkenboom et al., 2013). Furthermore, when OT occurs in a group setting, participants benefit from peer support and social interaction (Gauthier, Dalziel, \& Gauthier, 1987). Yoga and OT were merged in this study because they complement each other; yoga may improve symptoms of PD, while OT improves self-management of the disease.

Research is just beginning to document the relationship between fatigue and activity and participation levels in PD. More evidence is needed for effective interventions to manage nonmotor symptoms of PD, specifically fatigue. To our knowledge, this is the first study to merge two non-pharmacological treatments, yoga and OT, as a fall-risk management intervention for people with PD. This study will examine the relationship between fatigue and activity and participation levels, as well as the influence of the MY-OT-PD intervention on these constructs, and begin to fill this gap in research. 


\section{Ch. 2 Literature Review}

\subsection{Introduction}

This chapter will focus on a review of the literature on fatigue in Parkinson's disease (PD), the relationship between fatigue, falls, and activity and participation levels, and the evidence for yoga and occupational therapy (OT) interventions in PD. It will begin with an overview of PD, including descriptions of motor and non-motor symptoms of the disease. It will then expand upon the non-motor symptom, fatigue, and the potential causes of and current treatment options for fatigue. Following the review of fatigue, there will be a discussion on the relationship between fatigue, falling, and activity and participation. After that, there will be a review of the literature regarding yoga and OT interventions for this population. Finally, this chapter will conclude by identifying gaps in the research and justifying the need for this study.

\subsection{Overview of Parkinson's Disease}

\section{Incidence and Prevalence of Parkinson's Disease}

$\mathrm{PD}$ is a progressive, chronic neurodegenerative condition that is caused by the death of dopaminergic neurons often in the basal ganglia. Following Alzheimer's disease, it is the second most common neurological condition with at least one million people diagnosed in the United States (Bertram \& Tanzi, 2005; Lee \& Gilbert, 2016; Nassif \& Pereira, 2018; Nutt \& Wooten, 2005). About $1 \%$ of the population over 65 years old is diagnosed with PD, and that prevalence is expected to double by 2040 due to the aging of the population and longer lifespan expectancies (Nassif \& Pereira, 2018; Yan Yan Kwok et al., 2017). According to Foster, Bedekar, and TickleDegnen (2014) PD “is now considered a world health problem and health care priority” (p. 39). 


\section{Symptoms of Parkinson's Disease}

PD is generally characterized by motor symptoms including bradykinesia, rigidity, resting tremor, and postural instability (Davie, 2008; Nassif \& Pereira, 2018). Bradykinesia is slow movement, whereas rigidity is resistance to passive movement at joints (Nutt \& Wooten, 2005). The motor symptoms of PD are related to the decrease in dopaminergic neurons that occurs in the disease. These cardinal features of PD can range in severity, depending on the level of disease progression (Hoehn \& Yahr, 1967). As the disease progresses in severity so do the symptoms bradykinesia, rigidity, and postural instability, while resting tremor does not (Zuo et al., 2016).

Non-motor symptoms of PD include sleep disturbances, fatigue, depression, anxiety, autonomic dysfunction, dementia, and cognitive impairments (Bryant et al., 2012; Ongre et al., 2017). The non-motor symptoms of PD are often overlooked, not treated well, and reduce quality of life. Research in PD has traditionally focused on motor symptoms, but for the last two decades non-motor symptoms have been gaining attention. Fatigue is among one of the most common non-motor symptoms and will be addressed in detail later in this paper (Siciliano et al., 2017).

\section{Parkinson's Disease Severity Scale}

The symptoms of PD manifest in various forms of severity depending on where one is at in the disease progression. A person's degree of functional impairment, and therefore treatment options, will vary depending on their stage in disease progression. Thus, Hoehn and Yahr (1967) created the five stages of PD which are used to determine disease severity. The disease is considered stage one if it consists of involvement on one side of the body with minimal to no functional impairment. PD is considered stage two if the involvement affects both sides of the body, however not enough to cause a loss of balance. Stage three in PD disease severity includes 
involvement on both sides of the body with balance impairments emerging; the disease is mild to moderate in severity at this stage. Stage four in the disease progression is fully developed PD and is severely disabling, but the person can still walk with or without an assistive device. The final stage, stage five, is defined by one being confined to a bed or wheelchair unless aided.

Because some symptoms of PD have been shown to increase in severity as the disease progresses, it is helpful to know where one is at in disease progression. By knowing this, treatment intervention can be designed for the just right challenge of the person.

\section{Treatment in Parkinson's Disease}

Treatment in PD usually consists of both pharmacological and non-pharmacological options. There are several pharmacological treatment options, including drugs that return dopamine to the brain's motor control systems (Yan Yan Kwok et al., 2017). Levodopa treatment, which consists of medication being converted to dopamine in the brain, is the most common type of drug treatment for PD (Davie, 2008). Unfortunately, a side effect related to levodopa treatment, and specifically the duration and peak dose times of treatment, is dyskinesia. Dyskinesia is involuntary and uncontrolled movement, often in abnormal patterns. Another pharmacological treatment option includes dopamine agonists, which stimulate the parts of the brain activated by dopamine (Spears, 2018). There are many more pharmacological options for treatment in $\mathrm{PD}$, including MAO-B inhibitors, COMT inhibitors, and anticholinergic drugs to name a few (Davie, 2008). However, none of these drugs come without side effects and often do not manage multiple symptoms at once.

Non-pharmacological treatment options include exercise, activity, diet modifications and supplements, environmental modifications, and in some cases surgery to the contralateral thalamus (Davie, 2008). Because the side effects of pharmacological treatment can be disabling, 
more research on alternative treatment options is needed to provide people with PD with more choices.

\subsection{Fatigue in Parkinson's Disease}

\section{Defining Fatigue}

Defining fatigue in PD has proven difficult in research because fatigue is multidimensional and can be related to a number of compounding factors including emotional and social disorders (Nassif \& Pereira, 2018; Nijrolder et al., 2008). Bryant et al. (2012) defined fatigue as an "overwhelming sense of tiredness, lack of energy and often a feeling of total exhaustion” (p. 326). Kluger, Krupp, and Enoka (2013) suggested diagnostic criteria for fatigue in PD in which four of the following attributes must be present:

(i) Symptoms are induced by activities of daily living; (ii) symptoms occur with little or no exertion; (iii) symptoms limit the type, intensity, and duration of activities performed; (iv) Symptoms are not reliably relieved by rest or may require prolonged periods of rest;

(v) symptoms are brought on by cognitive tasks or situations requiring sustained attention, including social interactions; (vi) vigorous activities are avoided for fear of worsening symptoms; (vii) mild to moderate exertion worsens symptoms for hours to days; (viii) symptoms have a predictable diurnal pattern regardless of the activities performed; and (ix) symptoms are unpredictable and may have a sudden onset (Nassif \& Pereira, 2018, p. 147).

Nassif and Pereira (2018) added criteria for fatigue by suggesting the feeling of fatigue cannot be explained by the side-effects of drugs or psychiatric illness and is linked to fatiguerelated outcomes including decreased motivation and participation. Furthermore, fatigue in PD is distinctly different from normal sleepiness or tiredness, because people with tiredness can feel 
tiredness resolved after napping whereas people with fatigue remain fatigued (Nassif \& Pereira, 2018; Schiehser et al., 2013).

Broadly, there are two categories of fatigue in PD in the literature: objective (physiological) and subjective (pathological). Objective fatigue is the physiological fatigue or fatigability that can be measured as physical performance declines (Bryant et al., 2012; Nassif \& Pereira, 2018). Subjective fatigue is difficult to measure because it's composed of multiple facets including physical, social, emotional, and cognitive fatigue. This type of fatigue can be defined as pathological when "it has a duration of more than three months, is more intense than previously experienced fatigue, and compromises daily activities and quality of life" (Nassif \& Pereira, 2018, p. 144).

Because there are no established biological markers to measure subjective fatigue, it is often assessed through self-report questionnaires such as the Fatigue Severity Scale, Multidimensional Fatigue Inventory, and the Parkinson's Fatigue Scale (Siciliano et al., 2017). This study used focus group interviews and the Modified Fatigue Impact Scale (MFIS) to measure subjective fatigue in PD (Schiehser et al., 2013). The MFIS was chosen because it may be more responsive to change in PD-related fatigue than other scales (Kluger et al., 2016).

\section{Incidence and Prevalence of Fatigue in Parkinson's Disease}

The percentage of people who report fatigue in PD varies greatly, with between $33 \%$ and $81 \%$ of individuals with PD reporting fatigue (Kostić et al., 2016). This broad range could be due to inconsistencies in definition and measurement tools. Fatigue is often described as one of the most upsetting symptoms related to $\mathrm{PD}$, with "up to $1 / 3$ of PD patients report[ing] fatigue as their most disabling symptom” (Nassif \& Pereira, 2018, p.144). 
Fatigue is often related to comorbidities, which makes it difficult to identify and treat. Because fatigue correlates with depression, sleep disorders, etc., fatigue can be difficult to tease out as a primary manifestation of PD rather than secondary manifestation. However, fatigue is established as an independent symptom of PD. For example, in one study of sleep disorders in individuals with PD without depression, fatigue was reported by $43 \%$ of participants (Van Hilten et al., 1993). This is an important finding in research because it establishes fatigue as a primary manifestation of PD.

\section{Causes of Fatigue in Parkinson's Disease}

Because fatigue is a complex symptom of PD, understanding the cause of fatigue in PD is difficult. There are multiple factors that contribute to fatigue and more research is needed to further understand them. Some theories suggest there are potential biomarkers of fatigue, and that elevated levels of these biomarkers may increase fatigue (Kostić et al., 2016). These include inflammatory markers (as measured through spinal cerebral fluid levels), cytokines (cell signalers), and interleukin-6 (a specific cytokine). Other theories suggest that the dysfunction of systems, namely endocrine or hypothalamic-pituitary-adrenal, may be related to fatigue. There are more theories that suggest fatigue is related to circadian rhythm disorders, reduced perfusion in the frontal lobe, or decreased serotonergic marker in the basal ganglia and limbic structures (Nassif \& Pereira, 2018). The cause of fatigue is most likely related to a combination of factors rather than injury to one specific structure alone.

Zuo et al. (2016) demonstrated that fatigue worsens with disease severity. They studied fatigue in PD by comparing disease severity with serotonin levels as measured through cerebrospinal fluid. They discovered the two were negatively and significantly correlated, meaning that as the disease becomes more severe, the level of serotonin found in the 
cerebrospinal fluid decreases, which is related to more fatigue. Additionally, fatigue may be present from stage one in the progression of PD (Nassif \& Pereira, 2018).

\section{Treatment for Fatigue in Parkinson's Disease}

Because fatigue is a common and disabling symptom in PD, finding effective treatment interventions is important. Furthermore, fatigue across all populations accounts for $5-10 \%$ of primary care appointments demonstrating that effective intervention is needed (Nijrolder et al., 2008). Like treatment for PD, there are pharmacological and non-pharmacological options for the treatment of fatigue in PD. However, interventions for subjective fatigue in PD are not well established and further research is needed.

Elbers, Verhoef, van Wegen, Berendse, and Kwakkel (2015) did a review on interventions for subjective fatigue and found that only pharmacological interventions showed significant improvements, specifically the two drugs Doxepin and Rasagiline. Ongre et al. (2017) found that clients receiving dopamine agonists had a slightly better improvement in fatigue symptoms and severity than those receiving levodopa treatment. While the research on treatment for subjective fatigue in PD has shown some evidence to guide intervention planning, more research is needed. Nassif and Pereira (2018) suggested an approach to treating subjective fatigue in PD that should rely heavily on client education and awareness of fatigue as a symptom that hasn't yet been researched thoroughly.

\subsection{Relationship Between Fatigue and Falling in Parkinson's Disease}

\section{Overview of Falls in Parkinson's Disease}

People with PD have an increased risk of falling when compared to age-matched peers without PD, which is due to both the motor and non-motor symptoms of the disease. In fact, Bryant, Rintala, Hou, and Protas (2015) stated, "PD is one of the most common neurological 
conditions leading to falls" (p. 187). The prevalence of falls in PD was 60\% in one study done by Gazibara et al. (2015), however, retrospective studies have reported PD fall prevalence ranges from 38-68\%. People with PD are 2.7 times more likely to fall than other community-dwelling older adults (Bryant et al., 2012; Kader et al., 2016; Pickering et al., 2007). These numbers show that falling is an important concern for people with PD.

The risk of falling in PD is strongly linked to disease severity, and thus symptom severity (Wood et al., 2002). Both the non-motor and motor symptoms of PD lead to physical inactivity, which increases one's risk of falling (Bryant et al., 2015). Falls lead to increased dependency and decreased quality of life for people with PD (Wood et al., 2002). The motor impairments resulting from PD are obvious fall-risk factors because these symptoms create physical instability. Approximately $75 \%$ of people with PD have impaired balance (Lindholm, Hagell, Hansson, \& Nilsson, 2014) Other factors associated with falling in PD include a prior history of falls, duration and severity of the disease, cognitive dysfunction, fear of falling, and fatigue (Gazibara et al., 2015).

\section{Fatigue as a Fall-Risk Factor}

Fatigue in PD has been found to be one of "the most predictive clinical factors for worsening health-related quality of life in individuals with PD” (Bryant et al., 2012, p.327). Fatigue's relationship to falls was examined in a study done by Bryant et al. (2012). Participants with PD were separated into two categories: "fallers" (had at least one fall within the previous 6 months) and "non-fallers". Fatigue was compared between groups via the Iowa Fatigue Scale, a self-report questionnaire, and found to be reported higher in the "fallers" group. Furthermore, the fatigue measured in this study was classified into mental and physical components. Mental fatigue was defined as the subjective feeling of being mentally exhausted, while physical fatigue 
was defined as the subjective feeling of being physically exhausted. The "fallers" were found to have more physical fatigue but mental fatigue didn't differ across groups. This study is important because it shows that fatigue and falls may be related, yet certain aspects of fatigue may be more important to define as a fall-risk factor.

In another study, Bryant et al. (2015) researched falls in PD in order to understand the impact of falling on physical inactivity. They found that self-reported fatigue levels (as measured by the Iowa Fatigue Scale) correlated significantly with self-reported fall frequency $(p=0.02)$, such that as self-reported fatigue increased so did self-reported falls. This study is important because it quantifies the relationship between fatigue and the occurrence of falls in PD, justifying further research on these topics.

Rochester et al. (2004) expanded upon fatigue as a fall-risk factor, exploring the relationship of fatigue's impact on attentional capacity. Attentional capacity is limited in PD as cognitive impairments become more severe. Maintaining balance and coping with demands in the environment require attention. The reduced attentional capacity in PD may create a fall-risk for people with PD who are fatigued. Fatigue was found to have a negative relationship with attentional capacity, meaning the more fatigued one was the less attentional capacity they had, thus increasing their risk of falling. This study is important because it identified fatigue in PD as a fall-risk factor.

\subsection{Relationship Between Falling and Activity and Participation in Parkinson's Disease}

Activity and Participation have been defined by the International Classification of Functioning, Disability, and Health (ICF). Activity, as defined by the ICF, includes "execution of a task or action by an individual", while participation is defined as "involvement in a life situation" (WHO, 2002, p. 10). There are nine subdomains within ICF activity and participation 
including: 1) learning and applying knowledge; 2) general tasks and demands; 3)

communication; 4) mobility; 5) self-care; 6) domestic life; 7) interpersonal interactions and relationships; 8) major life areas; and 9) community, social and civic life. These subdomains are broad, showing that activity and participation cover multiple aspects of life.

People with PD experience limitations in activity and participation due to the motor and non-motor symptoms of the disease, including fatigue. More specifically, fatigue is a fall-risk factor and experiencing a fall can cause limitations because of injury, anxiety for falling in the future, and/or functional decline (Bryant et al., 2015). Bryant et al. (2015) demonstrated that falls and fear of falling were significantly associated with ADL limitations and physical inactivity in people with PD. Compared to controls without PD, people with PD were $29 \%$ less active (p.185). Furthermore, 44\% of people with PD who had experienced a fall described reduced activity and participation after the fall (Bryant et al., 2015; Kader et al., 2016).

People with PD who have fallen or have a fear of falling experience a significant amount of activity avoidance. According to a study by Kader et al. (2016) using the MSAFFE questionnaire, the most common activities that were avoided included "going out when it's slippery", "reaching for something above your head", "walking a kilometer", and "going to a place with crowds". Some of these avoidance mechanisms are actually fall prevention strategies, such as avoiding "going out when it's slippery". However, avoidance in some of these categories puts people at risk for decreased societal participation.

Much like fatigue, fall-related activity avoidance may be related to disease severity, but it is also seen in the early stages of PD (Kader et al., 2016). Activity avoidance is more prevalent in people who have experienced a fall or had a near-fall, but Kader et al. (2016) discovered that activity avoidance is present in participants who do not have a history of falls. This discovery 
suggests that activity avoidance is a problem that should be discussed with people with PD regardless of whether or not they've experienced a fall. Falls lead to dependency, decreased participation, decreased quality of life, and increased nursing home admissions (Wood et al., 2002). Because fall-related activity avoidance and fatigue most likely will worsen as the disease progresses, we need more strategies for people with PD to remain engaged in life.

\subsection{Relationship Between Fatigue and Activity and Participation in Parkinson's Disease}

Because activity and participation cover many domains, its relationship to fatigue is not fully understood. There are several studies that document a negative correlation between fatigue and physical activity or exercise participation. Garber and Friedman (2003) studied fatigue in PD to understand its relationship to physical activity. They discovered that "increased levels of fatigue were associated with decreased levels of leisure physical activity, lower frequency of vigorous physical activity, [and] less time spent moving about performing daily tasks each day..." (p. 1119). Additionally, Abrantes et al. (2012) researched how physical activity impacts fatigue, depression, and apathy in PD. They found an inverse relationship between physical activity and fatigue, meaning higher levels of physical activity significantly correlated with lower levels of fatigue.

A qualitative, grounded theory study by O’Brien, Clemson, and Canning (2016) examined the meaning of, and factors that influence, exercise participation in people with PD. Their results included four major themes: 1) adapting to change and loss; 2) the influence of others; 3) making sense of the exercise experience; and 4) hope for a more active future. Within the major theme adapting to change and loss, a subtheme of facing the challenges of fatigue and apathy occurred. Fatigue was perceived as a barrier to exercise participation. In combining the major themes and subthemes to understand the meaning of exercise participation, the authors 
suggested that participation in exercise was a way for participants to reframe their identity as "active" (Obrien, Clemson, \& Canning, 2016, p. 474). The authors also discovered new factors that contribute to decisions to participate in exercise, which included apathy and fatigue, a belief in a finite energy limit, and the importance of feedback from the physiotherapist.

McAuliffe et al. (2017) studied communicative participation in PD, defined as "taking part in life situations where knowledge, information, ideas or feelings are exchanged'” (p. 407). They found that greater perceived fatigue was associated with lower levels of communicative participation. While most of the research done on fatigue and activity and participation has looked at physical activity or exercise participation, this study is unique in examining communicative participation. There is limited literature on the relationship between fatigue and activity and participation in PD. More research is needed to understand how fatigue affects multiple domains of activity and participation.

\subsection{Yoga}

\section{Overview of Yoga}

Yoga is a preventative and restorative form of exercise that targets the mind, body, and spirit (Nayak \& Shankar, 2004). In the west, yoga typically consists of physical poses (asanas), breath work (pranayama), and mindfulness/meditation (dhyana). Yoga has many benefits, including increased physical strength and flexibility, increased energy and relaxation, improved sleep, reduced stress, and reduced fatigue (Boehm, Ostermann, Milazzo, \& Büssing, 2012). In a healthy population, yoga also improves cortisol levels which result in reduced anxiety, stress, and depression (Sharma et al., 2015). Additionally, the breath work done in yoga has positive benefits on autonomic functions and fostering self-awareness (Nayak \& Shankar, 2004). Yoga is holistic, bringing all aspects of a person into harmony. This mind-body connection is beneficial 
for populations that experience pain, physical restraints, and emotional difficulties, which are experienced in PD (Yan Yan Kwok et al., 2017).

\section{Yoga as an Intervention for Parkinson's Disease}

While the evidence of yoga as an intervention for PD is limited, the studies that exist have shown positive results. Because yoga can benefit both motor and non-motor functions, it is feasible and encouraging for use in people with PD. The mindfulness aspect of yoga can be therapeutic for the acceptance of disability (Yan Yan Kwok et al., 2017). According to Yan Yan Kwok et al. (2017), "a yoga intervention is hypothesized to help a person with PD to explore one's self-boundaries, redefine their illness experience, and self-transcend to attain a sense of wellbeing even in the vulnerable PD trajectory" (p. 3). Furthermore, people with chronic conditions reported benefits of yoga including improved well-being and quality of life (Sharma et al., 2015).

Yoga may create positive outcomes for the motor symptoms of PD including tremor, rigidity, bradykinesia, and postural instability. According to Sharma et al. (2015), people with PD who participated in yoga experienced a visible reduction in tremor that lasted for several hours afterward. In a randomized control study examining the effects of power yoga for people with PD, the intervention "significantly reduced bradykinesia and joint rigidity scores, increased muscular strength and power, and improved quality of life" (Ni, Mooney, \& Signorile, 2016, p. 130). Yoga also incorporates breath work into practice and therefore may have benefits for respiratory function and lowering blood pressure (Sharma et al., 2015).

Van Puymbroeck et al. (2018) completed a randomized controlled trial to test functional improvements in people with PD after an eight-week yoga intervention. They found statistically significant improvements within the control group for motor function as measured by the 
Movement Disorders Society-Sponsored Revision of the Unified Parkinson's Disease Rating Scale (UPDRS) and freezing of gait as measured by Freezing of Gait Questionnaire (FoG). They also found statistically significant improvements across groups in the Functional Gait Assessment (FGA). Additionally, substantial improvements were found in the modified Hoehn and Yahr staging of disease progression with reductions in stages two and three and increases in stage one; these changes suggest that yoga may help slow down the progression of PD. This study quantified and validated the use of yoga as an intervention for functional improvements in people with PD.

Hawkins et al. (2018) studied a therapeutic yoga intervention for people with PD to understand its effect on activity and participation, as understood from an ICF standpoint. Qualitative results of this study revealed perceived outcomes associated with six of the nine ICF activity and participation domains, including: 2) general tasks and demands; 4) mobility; 5) selfcare; 6) domestic life; 7) interpersonal interactions and relationships; and 9) community, social and civic life. This study is important as it supports the use of a community yoga program for people with PD to engage in multiple facets of activity and participation.

Another important way yoga may benefit people with PD is through improvement in the non-motor symptoms of the disease. People with PD who participated in yoga reported increased energy and relaxation, reduced fatigue, improved mood, positive social relationships, and attending to body signals more efficiently (Sharma et al., 2015). While more research for yoga in PD is needed, there has been some research examining the effects of yoga in multiple sclerosis (MS), a neurodegenerative condition. These studies have shown yoga to have a significant impact on fatigue, cognition, and quality of life in people with MS (Oken et al., 2004). Because 
MS and PD are both chronic, neurodegenerative conditions, these improved outcomes show potential for yoga as an intervention for PD.

\section{Yoga as an Intervention for Fatigue}

Research has shown controversial evidence for the effect of exercise on fatigue in PD (Winward et al., 2012). Walter et al. (2019) studied the effects of an eight-week therapeutic yoga program on PD-related fatigue, as measured by the Parkinson's Fatigue Scale, and discovered a significant improvement in fatigue in both the control and waitlist group. They suggested this waitlist group improvement could potentially be due to the waitlist group increasing physical activity in order to prepare for the upcoming yoga intervention. While evidence for yoga as an intervention to reduce fatigue in PD is limited, there is evidence of yoga reducing fatigue in other neurological populations, like those with MS (Oken et al., 2004).

As PD progresses, fatigue may progress in severity and limit attentional capacity (Rochester et al., 2004). Because of the mind-body connection that yoga offers, it may be beneficial in creating more deliberate attention to the body. This may rectify fatigue's negative effect on attentional capacity and reduce the risk of falling.

\subsection{Occupational Therapy Intervention for Parkinson's Disease}

The role of an occupational therapist is to promote and support a person's ability to engage in their ADLs, work, and leisure activities (Dixon et al., 2007). This is beneficial for a person with PD, as they may benefit from strategies and support to remain engaged for as long as possible throughout the disease progression. OT can provide that support through designing interventions that include the use of occupations and activities, preparatory methods and tasks, education and training, advocacy, and/or group interventions (American Occupational Therapy Association [AOTA], 2014). 
A randomized controlled trial conducted by Sturkenboom et al. (2013) tested the usefulness of OT interventions for daily activities of people with PD. They compared selfperceived performance in daily activities as measured by the Canadian Occupational Performance Measure (COPM) between one group receiving OT and a control group not receiving OT at both three months and six months after the intervention had started. They found a significant difference between groups on the COPM scores. Additionally, the group receiving OT significantly improved in their self-perceived performance of activities, satisfaction in their performance, and participation in IADLs. This study is important because it provides evidence that OT can be effective for improving performance in ADL/IADLs in people with PD.

In a systematic review of the literature, OT was found to be effective when providing interventions that targeted muscular strength, created environmental awareness and modifications, and taught behavioral self-management strategies (Foster et al., 2014). They found that interventions to strengthen or maintain strength need to be task-specific to show an improvement in performance skills. In order to create environmental awareness, Foster and colleagues found auditory cueing to be more successful than visual or tactile cues. Additionally, teaching cognitive and self-management strategies included education, setting goals, creating or maintaining healthy habits and routines, and providing feedback after task practice. This research provided evidence to support specific types of OT interventions for people with PD.

When OT occurs in a group setting, a major benefit of therapy is peer support. Group OT has shown positive benefits for people with chronic, degenerative conditions that result in social isolation and depression, specifically PD (Gauthier et al., 1987). People with PD are "at considerable risk of daily life and health care stigmatization and social isolation" (Foster et al., 2014, p. 44) Being in group OT may be therapeutic simply because of the peer support and 
socialization that occurs. Group delivery is an important method of OT service delivery that can improve psychological well-being and promote positive behavioral changes.

\subsection{Gaps in Research}

Because treatment in PD typically targets the motor symptoms, and non-motor symptoms often have a greater impact on quality of life, we need more research on effective treatment options that address the non-motor symptoms of the disease (Yan Yan Kwok et al., 2017). Fatigue is a non-motor symptom that is lacking effective treatment options. The combination of yoga and OT as an intervention specific to fatigue, to our knowledge, has not been studied in populations with PD. Because we are merging yoga and OT, this pilot study will begin to fill that gap in research.

Furthermore, the relationship between fatigue and activity and participation is not fully understood, as activity and participation cover many domains of life. Because this study will use the IMPACT-S scale to measure activity and participation, it will cover the nine domains of activity and participation. This study aims to explore the relationship between fatigue and multiple aspects of activity and participation, and therefore begin to fill this gap in the literature.

\subsection{Conclusion}

In summary, people with PD experience disabling motor and non-motor symptoms. Fatigue is a non-motor impairment that is often described as one of the most upsetting symptoms related to PD (Nassif \& Pereira, 2018). Furthermore, fatigue in PD has been found to be a fallrisk factor (Rochester et al., 2006). Both the experience of fatigue and falling have been shown to reduce activity and participation for people with PD (Bryant et al., 2015; O'Brien et al., 2016). Therefore, this study will explore the influence of a fall-risk management intervention, Merging Yoga and Occupational Therapy for Parkinson's Disease (MY-OT-PD), on fatigue and activity 
and participation levels, as well as the relationship between these constructs. This research aims to further the understanding of using two non-pharmacological treatment options to address fatigue and activity and participation in PD. 


\section{Ch. 3 Methods}

\subsection{Study Design}

This was a mixed methods pilot study using a convergent parallel design to analyze quantitative and qualitative data. This study explored aspects of the MY-OT-PD fall-risk management intervention related to measures of fatigue and activity and participation. Outcomes were measured at three separate eight-week intervals: baseline (followed by an eight week control period), pre-intervention, and post-intervention. Focus groups were completed at the conclusion of the study to qualitatively explore participants' perceptions of the intervention related to their fatigue and activity and participation levels.

\subsection{Recruitment and Participants}

After IRB approval, participants were recruited from a convenience sample of one of the following: people attending a community based "yoga for PD" class held at a local athletic center, people attending a PD support group, or flyers in the community. Originally there were 18 participants, however, one participant dropped out during the control period before the start of intervention due to the commitment being too much. Inclusion criteria included: a self-reported diagnosis of PD; being 18 years of age or older; scoring greater than or equal to 4/6 on the Short Mini Mental Status Exam (Dahlke, Curtis, Federman, \& Wolf, 2014); having the ability to stand with or without an assistive device; having the ability to speak and communicate in English; and having transportation to the local athletic center to participate in assessments and the MY-OTPD program. All participants provided written consent.

\subsection{Intervention}

Participants engaged in MY-OT-PD twice a week for eight weeks (i.e. 14 sessions, one week off for holiday break). The program consisted of two parts: 75 minutes of yoga and one 
hour of group OT. On average, $12.82 \pm 1.31$ sessions were attended. Classes were missed secondary to family obligations and medical appointments.

The yoga portion was taught by a certified yoga teacher with over four years of experience leading weekly adaptive yoga classes designed for people with PD. Yoga consisted of physical postures (asana) in seated, standing, and floor positions. Breathing (pranayama) was incorporated into each session by pairing breath with the physical postures (i.e. inhaling and exhaling with movement). Mindfulness (dhyana) was incorporated as the instructor began each session with an introduction to mindfulness and guided participants' thoughts throughout the session. Additionally, each session included specific techniques to target PD symptoms (i.e. emphasis on exaggerated vocalization and facial movements).

The group OT sessions were taught by a registered and licensed OT with five years of clinical experience. Group OT included topics such as managing symptoms of PD (including over three sessions dedicated to fatigue management), managing the environment, and changing attitudes and behaviors (see Table 3.1). MY-OT was originally developed for clients with stroke but refined to meet the needs of people with PD (Schmid, Van Puymbroeck, Portz, Atler, \& Fruhauf, 2016). For example, symptoms of PD were included in MY-OT-PD where it was not included in MY-OT for stroke. 
Table 3.1: Weekly Group OT Topics

\begin{tabular}{|l|l|l|}
\hline Week & Session & Group OT Topics \\
\hline 1 & 1 & Program overview; introduction to falls \\
\hline & 2 & Intro to WHO model; fear of falling \\
\hline & 4 & Fall analysis; personal action plans \\
\hline 3 & 5 & Effects of PD and their role in falls \\
\hline & 6 & Physical activity and falls \\
\hline 4 & 7 & Physical activity, endurance, and fatigue part 1 \\
\hline 5 & 8 & Physical activity, endurance, and fatigue part 2 \\
\hline & 10 & Activity modification for fatigue management \\
\hline 6 & 11 & Fall hazards in the home and community \\
\hline & 12 & Fall management and advocacy \\
\hline 7 & 13 & Fall management and case studies \\
\hline & 14 & Program review \\
\hline
\end{tabular}

\subsection{Data Collection}

\section{Quantitative Data}

All data were collected by the principal investigator of the study or a trained research assistant. Quantitative measurement tools included the Modified Fatigue Impact Scale (MFIS) and the ICF Measure of Participation and Activities Screener (IMPACT-S) (Post et al., 2008; Schiehser et al., 2013). The participants took these assessments electronically or on paper at three separate eight-week intervals throughout the study: baseline, pre-intervention, and postintervention. 
The MFIS is a self-report questionnaire that measures fatigue through 21 items which are ranked on a scale from 0 ("never") to 4 ("almost always"). The MFIS was derived from the Fatigue Impact Scale; the MFIS assesses multiple facets of fatigue, including physical, cognitive and psychosocial functioning (Schiehser et al., 2013). Total scores are calculated by adding responses and can range from 0 to 84 , with higher scores indicating greater fatigue. The MFIS has been validated for use in people with PD without dementia; internal consistency reliability was high for all 21 items, concurrent validity was excellent, and convergent validity was strong (Kluger, Garimella, \& Garvan, 2017; Schiehser et al., 2013).

The IMPACT-S is a self-report questionnaire that measures activity and participation based on all nine activity and participation domains as defined in the ICF (Van der Zee et al., 2010). IMPACT-S consists of 32 questions which are rated on a scale from 1 ("no limitations whatsoever") to 4 ("I cannot do that at all"). Total scores are calculated by adding up responses, with higher scores indicating greater impairment. Psychometric properties of IMPACT-S have been tested in road accident victims; internal consistency reliability was good to excellent for all scale scores, and test-retest reliability was moderate to substantial for all questions but excellent for total scores of activity and participation (Post et al., 2008). While IMPACT-S has not yet been used for PD, it has been used to measure activity and participation in other populations with neurological conditions, such as stroke (Miller et al., 2013).

\section{Qualitative Data}

Two semi-structured focus groups $(n=11, n=5)$ were conducted at the end of the intervention by a trained Ph.D. candidate unaffiliated with the study. One participant was unable to attend the focus groups due to illness. Questions qualitatively examined participants’ perception of how their fatigue and activity and participation levels were influenced by the 
intervention. Two of the questions, among others, included: 1) "what did you learn to manage fatigue" with a probe "what did you learn in yoga vs occupational therapy class", and 2) "how has your management of fatigue influenced what you need and want to do"?

\subsection{Data Analyses}

\section{Quantitative Data}

Quantitative data were analyzed using SPSS 25 software (SPSS Inc, Chicago, IL). Data were transformed replacing missing values using the series mean. Demographic data were described with means, standard deviations, frequencies, and percentages. Analyses revealed no significant differences between baseline and pre-intervention outcome measure data. Therefore, baseline and pre-intervention data were averaged and the new mean and standard deviation were used as pre-intervention scores. Outcome measure data were analyzed for normality using a Schapiro-Wilk test and all data were normal. As data were normal, paired $t$-tests were used to compare pre-intervention and post-intervention scores. Furthermore, fatigue and activity and participation measures were correlated.

\section{Qualitative Data}

The final focus groups were recorded and transcribed verbatim into word processing files. The transcripts were analyzed using NVivo 12 software (QSR International, Melbourne, Australia). Transcripts were coded using two methods independent of each other: inductive and deductive coding (see Table 3.2). First, transcripts were inductively coded allowing codes to emerge from the data to capture the participants' experience. Then, transcripts were deductively coded using all nine ICF activity and participation domains. Once both inductive and deductive codes were generated, codes were organized together to create major themes and subthemes. To ensure rigor, an audit trail was kept and a triangulating analyst also coded the data. Furthermore, 
triangulation was used by comparing the focus group facilitator notes to transcripts. Codes were peer-reviewed by a committee member who wasn't involved with the participants of the study. 
Table 3.2: Qualitative Analysis

\begin{tabular}{|c|c|c|c|}
\hline Data Examples & Inductive Codes & $\begin{array}{l}\text { Deductive Codes } \\
\text { (9 ICF Activity and } \\
\text { Participation } \\
\text { Domains) }\end{array}$ & Major Themes: Subthemes \\
\hline "Giving myself permission to rest" & Learning to accept fatigue & & $\begin{array}{l}\text { Managing Fatigue: "Paying } \\
\text { Attention and Acting }\end{array}$ \\
\hline "Exercise helps my fatigue in the afternoon" & Exercise for fatigue & & $\begin{array}{l}\text { Accordingly": } \\
\text { Fatigue Awareness } \\
\text { Fatigue Acceptance } \\
\text { Using Rest and Exercise }\end{array}$ \\
\hline $\begin{array}{l}\text { "I learned to keep reviewing the conditions in } \\
\text { my house to make sure they're safe" }\end{array}$ & Household safety & $\begin{array}{l}\text { Learning and applying } \\
\text { knowledge }\end{array}$ & \multirow{2}{*}{$\begin{array}{l}\text { Creating Mindfulness in Daily } \\
\text { Activities: } \\
\text { Environmental Awareness } \\
\text { Body Awareness } \\
\text { Doing More or Less }\end{array}$} \\
\hline $\begin{array}{l}\text { "Mindful[ness] with movement are two things } \\
\text { it [MY-OT-PD] really helped me with" }\end{array}$ & Mindfulness in body & Mobility & \\
\hline "Everybody in here is in the same boat" & $\begin{array}{l}\text { Shared experience/ } \\
\text { comradery }\end{array}$ & $\begin{array}{l}\text { Community, social, and } \\
\text { civic life }\end{array}$ & \multirow{2}{*}{$\begin{array}{l}\text { Giving and Receiving Within } \\
\text { a Community: } \\
\text { Comradery } \\
\text { Giving Back } \\
\text { Motivation }\end{array}$} \\
\hline "We're not just taking we're giving too" & $\begin{array}{l}\text { Transactional } \\
\text { relationships/ } \\
\text { contributing }\end{array}$ & Major life areas & \\
\hline $\begin{array}{l}\text { "It takes a little while before the words will } \\
\text { come up, and I don't feel bad about it } \\
\text { anymore it's like, this is normal" }\end{array}$ & $\begin{array}{l}\text { Self-compassion/ cutting } \\
\text { yourself some slack }\end{array}$ & Communication & \multirow{2}{*}{$\begin{array}{l}\text { Strengthening Relationship to } \\
\text { Self and Others: } \\
\text { Self-Compassion } \\
\text { Advocating }\end{array}$} \\
\hline $\begin{array}{l}\text { "I've been really calling my spouse out on it } \\
\text { lately and, telling him you have to know how } \\
\text { much more sensitive I am" }\end{array}$ & Educating partners & $\begin{array}{l}\text { Interpersonal } \\
\text { interactions and } \\
\text { relationships }\end{array}$ & \\
\hline
\end{tabular}




\section{Ch. 4 Manuscript}

\subsection{Introduction}

Parkinson's disease (PD) is a chronic, neurodegenerative condition caused by the death of dopaminergic neurons in the basal ganglia, resulting in significant motor and non-motor impairments (Lee \& Gilbert, 2016). Fatigue is a non-motor impairment often described as one of the most upsetting symptoms related to PD (Nassif \& Pereira, 2018). Furthermore, fatigue in PD is a documented fall-risk factor (Rochester et al., 2006). Both the experience of fatigue and falling have been shown to reduce activity and participation for people with PD (Bryant et al., 2015; O'Brien et al., 2016). Yet, few interventions exist to address these impairments. Therefore, the purpose of this pilot study was to explore the influence of a fall-risk management intervention, Merging Yoga and Occupational Therapy for Parkinson's Disease (MY-OT-PD), on fatigue and activity and participation levels, as well as the relationship between these constructs.

\subsection{Literature Review}

Fatigue in PD is multidimensional and can be related to a number of compounding factors (Nijrolder et al., 2008). Broadly, there are two types of fatigue in PD, objective and subjective. Objective fatigue is physiological fatigue that can be measured as physical performance declines. Subjective fatigue includes physical, social, emotional, and cognitive fatigue, and occurs when one feels exhausted in any of these categories (Nassif \& Pereira, 2018). Because there are no biological markers for measuring subjective fatigue, it is often measured through self-report assessments (Siciliano et al., 2017). The percentage of people with PD reporting fatigue varies greatly- between $33-81 \%$; this broad range may be due to inconsistencies 
in definition and measurement tools (Kostić et al., 2016). Throughout the remainder of this paper, any mention of fatigue refers to subjective fatigue.

Fatigue, falls, and activity and participation are connected in PD. For example, fatigue is a documented fall-risk factor. Bryant et al. (2012) found fatigue in PD to be present more significantly in people who had fallen when compared to non-fallers. Furthermore, people with PD are 2.7 times more likely to experience falls than age-matched peers, which is due to both the motor and non-motor symptoms of the disease, including fatigue (Kader et al., 2016; Pickering et al., 2007). In a recent study, $70 \%$ of people with PD experienced a fall within one year (Van Puymbroeck et al., 2018). When people with PD experience a fall, it can lead to injury, fear of falling, and reduced activity and participation (Wood et al., 2002). Falling and fear of falling are associated with activity limitations and physical inactivity in people with PD. Specifically, Kader et al. (2016) found that $41 \%$ of people with PD who had experienced a fall also described reduced activity and participation post-fall.

Activity and participation, defined by the International Classification of Functioning, Disability, and Health (ICF), is composed of nine domains including: 1) learning and applying knowledge; 2) general tasks and demands; 3) communication; 4) mobility; 5) self-care; 6) domestic life; 7) interpersonal interactions and relationships; 8) major life areas; and 9) community, social and civic life (WHO, 2002). The relationship between activity and participation and fatigue in PD is not fully understood as both constructs are complex and dynamic. Several studies have shown negative correlations between fatigue and physical activity (Garber \& Friedman, 2003; Müller et al., 2013). McAuliffe et al. (2017) studied communicative participation in $\mathrm{PD}$, defined as " taking part in life situations where knowledge, information, ideas or feelings are exchanged"' (p. 407), and found a negative association between fatigue and 
communicative participation. Because activity and participation cover a broad scope of domains, more research is needed to better understand the relationship with fatigue in PD.

Treatment in PD consists of pharmacological and non-pharmacological options. Many pharmacological treatment options come with negative side effects and poorly manage nonmotor symptoms (Davie, 2008). Yoga, as a non-pharmacological intervention for PD, is beneficial for both the motor and non-motor symptoms of the disease (Hawkins et al., 2018; Van Puymbroeck et al., 2018; Walter et al., 2019). According to Sharma et al. (2015), people with PD who participated in yoga reported: increased energy and relaxation; reduced fatigue; improved mood; positive social relationships; visible reduction in tremor; and attending to body signals more efficiently. Occupational therapy (OT) is a non-pharmacological treatment option that is beneficial for people with PD because OT supports and promotes a person's ability to engage in desired roles (Dixon et al., 2007; Sturkenboom et al., 2013).

Research is just beginning to document the relationship between fatigue and activity and participation levels in PD. More evidence is needed for effective interventions to manage the non-motor symptoms of PD, specifically fatigue. To our knowledge, this is the first study to merge two non-pharmacological treatments, yoga and OT, as a fall-risk management intervention for people with PD. Specifically, this study examined the relationship between fatigue and activity and participation measures and how each changed with the MY-OT-PD intervention.

\subsection{Methods}

\subsubsection{Study Design}

This was a mixed methods pilot study incorporating a convergent parallel design to analyze quantitative and qualitative data (Schoonenboom \& Johnson, 2017). This study explored 
aspects of the MY-OT-PD fall-risk management intervention related to measures of fatigue and activity and participation. Outcomes were measured at three separate eight-week intervals: baseline (followed by an eight-week control period), pre-intervention, and post-intervention. Focus groups were completed at the conclusion of the study to qualitatively explore participants' perceptions of the intervention related to their fatigue and activity and participation levels.

\subsubsection{Recruitment and Participants}

After IRB approval, participants were recruited from a convenience sample of one of the following: people attending a community based "yoga for PD" class held at a local athletic center, people attending a PD support group, or flyers in the community. Originally there were 18 participants, however, one participant dropped out during the control period before the start of intervention due to the commitment being too much. Inclusion criteria included: a self-reported diagnosis of PD; being 18 years of age or older; scoring greater than or equal to $4 / 6$ on the Short Mini Mental Status Exam (Dahlke et al., 2014); having the ability to stand with or without an assistive device; having the ability to speak and communicate in English; and having transportation to the local athletic center to participate in assessments and the MY-OT-PD program. All participants provided written consent.

\subsubsection{Intervention}

Participants engaged in MY-OT-PD twice a week for eight weeks (i.e. 14 sessions, one week off for holiday break). The program consisted of two parts: 75 minutes of yoga and one hour of group OT. On average, $12.82 \pm 1.31$ sessions were attended. Classes were missed secondary to family obligations and medical appointments. MY-OT-PD is described in greater detail elsewhere (Swink et al., 2019). 
The yoga portion was taught by a certified yoga teacher with over four years of experience leading weekly adaptive yoga classes designed for people with PD. Yoga consisted of physical postures (asana) in seated, standing, and floor positions. Breathing (pranayama) was incorporated into each session by pairing breath with the physical postures (i.e. inhaling and exhaling with movement). Mindfulness (dhyana) was incorporated as the instructor began each session with an introduction to mindfulness and guided participants' thoughts throughout the session. Additionally, each session included techniques specific to targeting PD symptoms (i.e. use of weighted sandbags and emphasis on exaggerated vocalization and facial movements).

The group OT sessions were taught by a registered and licensed OT with five years of clinical experience. Group OT included topics such as managing symptoms of PD (including over three sessions dedicated to fatigue management), managing the environment, and changing attitudes and behaviors (see Table 4.1). MY-OT was originally developed for clients with stroke but refined to meet the needs of people with PD (Schmid et al., 2016). For example, symptoms of PD were included in MY-OT-PD where it was not included in MY-OT for stroke. 
Table 4.1: Weekly Group OT Topics

\begin{tabular}{|l|l|l|}
\hline Week & Session & Group OT Topics \\
\hline 1 & 1 & Program overview; introduction to falls \\
\hline & 2 & Intro to WHO model; fear of falling \\
\hline & 4 & Fall analysis; personal action plans \\
\hline 3 & 5 & Effects of PD and their role in falls \\
\hline & 6 & Physical activity and falls \\
\hline 4 & 7 & Physical activity, endurance, and fatigue part 1 \\
\hline 5 & 8 & Physical activity, endurance, and fatigue part 2 \\
\hline & 10 & Activity modification for fatigue management \\
\hline 6 & 11 & Fall hazards in the home and community \\
\hline & 12 & Fall management and advocacy \\
\hline 7 & 13 & Fall management and case studies \\
\hline & 14 & Program review \\
\hline
\end{tabular}

\subsubsection{Data Collection}

\section{Quantitative Data}

All data were collected by the principal investigator of the study or a trained research assistant. Quantitative measurement tools included the Modified Fatigue Impact Scale (MFIS) and the ICF Measure of Participation and Activities Screener (IMPACT-S) (Post et al., 2008; Schiehser et al., 2013). The participants took these assessments electronically or on paper at three separate eight-week intervals throughout the study: baseline, pre-intervention, and postintervention. 
The MFIS is a self-report questionnaire that measures fatigue through 21 items which are ranked on a scale from 0 ("never") to 4 ("almost always"). The MFIS was derived from the Fatigue Impact Scale; the MFIS assesses multiple facets of fatigue, including physical, cognitive and psychosocial functioning (Schiehser et al., 2013). Total scores are calculated by adding responses and can range from 0 to 84 , with higher scores indicating greater fatigue. The MFIS has been validated for use in people with PD without dementia; internal consistency reliability was high for all 21 items, concurrent validity was excellent, and convergent validity was strong (Kluger et al., 2017; Schiehser et al., 2013).

The IMPACT-S is a self-report questionnaire that measures activity and participation based on all nine activity and participation domains as defined in the ICF (Van der Zee et al., 2010). IMPACT-S consists of 32 questions which are rated on a scale from 1 ("no limitations whatsoever") to 4 ("I cannot do that at all"). Total scores are calculated by adding up responses, with higher scores indicating greater impairment. Psychometric properties of IMPACT-S have been tested in road accident victims; internal consistency reliability was good to excellent for all scale scores, and test-retest reliability was moderate to substantial for all questions but excellent for total scores of activity and participation (Post et al., 2008). While IMPACT-S has not yet been used for PD, it has been used to measure activity and participation in other populations with neurological conditions, such as stroke (Miller et al., 2013).

\section{Qualitative Data}

Two semi-structured focus groups $(n=11, n=5)$ were conducted at the end of the intervention by a trained Ph.D. candidate unaffiliated with the study. One participant was unable to attend the focus groups due to illness. Questions qualitatively examined participants' perception of how their fatigue and activity and participation levels were influenced by the 
intervention. Two of the questions, among others, included: 1) "what did you learn to manage fatigue" with a probe "what did you learn in yoga vs occupational therapy class", and 2) "how has your management of fatigue influenced what you need and want to do"?

\subsubsection{Data Analyses}

\section{Quantitative Data}

Quantitative data were analyzed using SPSS 25 software (SPSS Inc, Chicago, IL). Data were transformed replacing missing values using the series mean. Demographic data were described with means, standard deviations, frequencies, and percentages. Analyses revealed no significant differences between baseline and pre-intervention outcome measure data. Therefore, baseline and pre-intervention data were averaged and the new mean and standard deviation were used as pre-intervention scores. Outcome measure data were analyzed for normality using a Schapiro-Wilk test and all data were normal. As data were normal, paired $t$-tests were used to compare pre-intervention and post-intervention scores. Furthermore, fatigue and activity and participation measures were correlated.

\section{Qualitative Data}

The final focus groups were recorded and transcribed verbatim into word processing files. The transcripts were analyzed using NVivo 12 software (QSR International, Melbourne, Australia). Transcripts were coded using two methods independent of each other: inductive and deductive coding (see Table 4.2). First, transcripts were inductively coded allowing codes to emerge from the data to capture the participants' experience. Then, transcripts were deductively coded using all nine ICF activity and participation domains. Once both inductive and deductive codes were generated, codes were organized together to create major themes and subthemes. To ensure rigor, an audit trail was kept and a triangulating analyst also coded the data. Furthermore, 
triangulation was used by comparing the focus group facilitator notes to transcripts. Codes were peer-reviewed by a committee member who wasn't involved with the participants of the study. 
Table 4.2: Qualitative Analysis

\begin{tabular}{|c|c|c|c|}
\hline Data Examples & Inductive Codes & $\begin{array}{l}\text { Deductive Codes } \\
\text { (9 ICF Activity and } \\
\text { Participation } \\
\text { Domains) }\end{array}$ & Major Themes: Subthemes \\
\hline "Giving myself permission to rest" & Learning to accept fatigue & & $\begin{array}{l}\text { Managing Fatigue: "Paying } \\
\text { Attention and Acting }\end{array}$ \\
\hline "Exercise helps my fatigue in the afternoon" & Exercise for fatigue & & $\begin{array}{l}\text { Accordingly": } \\
\text { Fatigue Awareness } \\
\text { Fatigue Acceptance } \\
\text { Using Rest and Exercise }\end{array}$ \\
\hline $\begin{array}{l}\text { "I learned to keep reviewing the conditions in } \\
\text { my house to make sure they're safe" }\end{array}$ & Household safety & $\begin{array}{l}\text { Learning and applying } \\
\text { knowledge }\end{array}$ & \multirow{2}{*}{$\begin{array}{l}\text { Creating Mindfulness in Daily } \\
\text { Activities: } \\
\text { Environmental Awareness } \\
\text { Body Awareness } \\
\text { Doing More or Less }\end{array}$} \\
\hline $\begin{array}{l}\text { "mindful[ness] with movement are two things } \\
\text { it [MY-OT-PD] really helped me with" }\end{array}$ & Mindfulness in body & Mobility & \\
\hline "Everybody in here is in the same boat" & $\begin{array}{l}\text { Shared experience/ } \\
\text { comradery }\end{array}$ & $\begin{array}{l}\text { Community, social, and } \\
\text { civic life }\end{array}$ & \multirow{2}{*}{$\begin{array}{l}\text { Giving and Receiving Within } \\
\text { a Community: } \\
\text { Comradery } \\
\text { Giving Back } \\
\text { Motivation }\end{array}$} \\
\hline "We're not just taking we're giving too" & $\begin{array}{l}\text { Transactional } \\
\text { relationships/ } \\
\text { contributing }\end{array}$ & Major life areas & \\
\hline $\begin{array}{l}\text { "It takes a little while before the words will } \\
\text { come up, and I don't feel bad about it } \\
\text { anymore it's like, this is normal" }\end{array}$ & $\begin{array}{l}\text { Self-compassion/ cutting } \\
\text { yourself some slack }\end{array}$ & Communication & \multirow{2}{*}{$\begin{array}{l}\text { Strengthening Relationship to } \\
\text { Self and Others: } \\
\text { Self-Compassion } \\
\text { Advocating }\end{array}$} \\
\hline $\begin{array}{l}\text { "I've been really calling my spouse out on it } \\
\text { lately and, telling him you have to know how } \\
\text { much more sensitive I am" }\end{array}$ & Educating partners & $\begin{array}{l}\text { Interpersonal } \\
\text { interactions and } \\
\text { relationships }\end{array}$ & \\
\hline
\end{tabular}




\subsection{Results}

\subsubsection{Quantitative Data}

Of the 17 participants who completed the study, 10 were male and seven were female. The average participant age was 72 years (range 64 to 82 years). The average time since diagnosis was seven years (range $<1$ to 18 years) (see Table 4.3).

Table 4.3: Demographics

\begin{tabular}{|l|l|}
\hline Characteristics & Total (n=17) \\
\hline Age (years), M \pm SD & $71.94 \pm 4.49$ \\
\hline Time since PD diagnosis (years), M \pm SD & $6.93 \pm 5.45$ \\
\hline Sex (male) & $10(58.8 \%)$ \\
\hline Race (white) & $17(100 \%)$ \\
\hline Education ('some college' and above) & $15(88.2 \%)$ \\
\hline Married or partnered ('yes') & $13(76.5 \%)$ \\
\hline Lives with others ('yes') & $15(88.2 \%)$ \\
\hline
\end{tabular}

Correlations of the MFIS and IMPACT-S scores were significant at both time points; the correlation at pre-intervention data collection was strong $(r=.760, p<.001)$ (Watkins \& Portney, 2009), indicating that fatigue and activity and participation was correlated. The means and standard deviations of MFIS and IMPACT-S scores at pre- and post-intervention are show in Table 4.4. There was a significant difference between pre-and post-intervention scores on the IMPACT-S $(60.32 \pm 13.02$ vs. $55.57 \pm 14.18, p=0.012)$. There were no significant changes in MFIS scores. 
Table 4.4: Quantitative Results: Means, Standard Deviations, Paired T-tests

\begin{tabular}{|l|l|l|l|l|}
\hline $\begin{array}{l}\text { Outcome } \\
\text { Measures }\end{array}$ & $\begin{array}{l}\text { Pre- } \\
\text { intervention }\end{array}$ & $\begin{array}{l}\text { Post- } \\
\text { intervention }\end{array}$ & $\begin{array}{l}\text { Significance* } \\
(\boldsymbol{p} \text {-value })\end{array}$ & Percent change \\
\hline MFIS $(\mathrm{n}=17)$ & $38.93 \pm 17.16$ & $39.94 \pm 13.60$ & 0.646 & $\uparrow 3 \%$ \\
\hline $\begin{array}{l}\text { IMPACT-S } \\
(\mathrm{n}=17)\end{array}$ & $60.32 \pm 13.02$ & $55.57 \pm 14.18$ & 0.012 & $\downarrow 8 \%$ \\
\hline
\end{tabular}

*significant at $\mathrm{p} \leq .05$

\subsubsection{Qualitative Data}

\section{Theme 1: Managing Fatigue: "Paying Attention and Acting Accordingly"}

Fatigue Awareness. Participants commonly described that MY-OT-PD helped them develop an increased awareness of fatigue and its effect on their daily activities. For example, some participants discussed enhanced insights about fatigue management beginning with awareness or "paying attention to it" (Participant-15). Participants learned to distinguish between mental and physical fatigue, understanding that the types of fatigue can contribute to one another or occur individually. Participant-9 talked about how he learned that his mental and physical fatigue are related when he said:

I've found out fatigue comes from sitting more than what I do. And if I'm just looking through boring stuff when a commercial comes up, I get up and walk around. But if I hit something that's really interesting and I concentrate on it then when it's over and I go to get up I'm tired, and my balance is off, and I want my cane.

Fatigue Acceptance. Another component that participants shared as part of learned fatigue management was accepting fatigue rather than fighting it, illustrated when Participant-11 said, "accept it [fatigue]...that's the way it is...it's ok." Participants expressed learning to give oneself permission to rest or respond how one's body needed. Participants felt that MY-OT-PD 
helped normalize the experience of fatigue. For example, Participant-7 said, “...somedays you're just not up to par and that makes us normal."

Using Rest and Exercise. Participants shared that as their fatigue awareness increased, so did their ability to detect whether they needed rest or exercise to manage fatigue. For example, Participant-3 learned that his stress and fatigue levels were connected and he needed exercise to work through those, illustrated when he said, "Yeah, fatigue has got a lot to do with stress, and obviously yoga is a way to attack that." On the contrary, Participant-5 learned that rest helped his fatigue, illustrated when he said, “...Learning to relax...it's a good way to [let go of] a lot of tension, you think it would prevent some fatigue."

Furthermore, participants commented on both the OT and yoga components of the intervention being helpful in managing fatigue as the OT component allowed discussion around awareness and strategies for fatigue management, while the yoga sessions provided an opportunity to address fatigue through either rest or exercise. Participant-7 expressed how yoga was both an opportunity to exercise and rest when she said:

When you're doing things like making an appointment and it's not working, then you get anxious and get all excited but that just tears down your body and I find that that's what's fatiguing, is this not being able to control what you're doing. And then I had trouble going to rest because of that...I think yoga helps you in seeing you can have a workout, get your body moving, and then still have that time to get some rest. And it just makes your day go better...I think at different times, certain fatigue things need to be worked out through a workout, so you rest better. 


\section{Theme 2: Creating Mindfulness in Daily Activities}

As participants discussed how MY-OT-PD helped them in their daily activities, a major theme of mindfulness emerged. Many participants remarked on how they learned to "slow down, stop and think about it" (Participant-15) before undergoing a task. Participants noted that mindfulness created a way for them to exercise power over their situation. For example, Participant-2 said, 'I can’t guarantee I'll never fall... just paying attention and maybe not taking a risk at certain times it helps out. So I do have a chance, uh I can make some choices to influence that."

Environmental Awareness. Participants commonly attributed an increase in environmental awareness to the OT classes. Many participants shared perceptions of increased attention to "safety in the house" (Participant-4) and the physical environment during daily activities. Some participants shared that this increased awareness of their environment gave them more confidence to engage in daily activities. Additionally, participants noted that through MYOT-PD their perception of the environment was becoming more mindful, illustrated when Participant-9 said, "Well I think analyzing the falls, the biological factors, and physical factors makes a difference cause then you look at things differently." Participant-11 shared a similar sentiment when she said, "It's [OT classes] brought a lot of things into focus for me."

Body Awareness. Participants commonly discussed how the yoga classes helped them increase their body awareness (being more mindful of their body). For example, Participant-3 said, "I was intrigued by why we had yoga. Why yoga for PD? ...it's just becoming aware of your body in particular ways.” Participant-17 remarked, “...to me yoga is a piece of it...it's the part that really helps my muscles stretch out and get rid of some of the tightness." In paying closer attention to their body, participants commented on perceived increased ability to manage 
fatigue. For example, Participant-7 commented on how the yoga classes helped her relax after the OT classes when she said:

I think having the class and being quiet and thinking and then going in and doing the yoga and um it kinda got your mind relaxing and um, after all the thinking... I think that was a nice follow through for the whole class.

Doing More or Less. Participants described being mindful in changing their activities to do more or less, depending on their fatigue levels. Some participants noted that, through MYOT-PD, they learned to do less or take things out of their daily routine to accommodate fatigue. Examples of doing less included not making the bed, not multitasking, and giving up being an election judge. On the contrary, some participants discussed how managing their fatigue enabled them to do more activities throughout the day. For example, Participant-4 said:

I...can walk without this stick now. I use it just for safety uh, purposes um I'm doing a lot of things that I used to try to do but I couldn't do... I vacuum our house. That was a hard thing to go ahead and do. I'm doing it. I'm cooking more. I- it [MY-OT-PD] just changed my whole life.

\section{Theme 3: Giving and Receiving Within a Community}

Comradery. One of the most reoccurring ideas shared by participants was the sense of community and comradery that MY-OT-PD provided. Participants expressed sentiments that the intervention provided a safe place and space to "live with it [PD], deal with it, talk with someone who might have the same thing" (Participant-14). Participants felt that the group dynamics were encouraging of one another, for example, Participant-11 said, “It's the act of hearing each other's stories...call it synergy, we feed on each other's energy." 
Many participants viewed the feeling of comradery as one of the most important things gained from the intervention. This is illustrated in the following two quotes:

I've had a problem all my life of shooting my mouth off. And one thing I've appreciated in this group is that uh, you didn't seem to mind too much [laughter]...it's one of the things that I've been most appreciative of... There's a lot of societal support and it couldn't be a better illustration of that then this very class. It's really something very wonderful...that we're human beings and we care about each other (Participant-3). I think what I liked the best was the group and seeing myself in everybody else and having that reflected back to me, and seeing the kindness and the humanity of the group and what they're going through...that's what was the best for me (Participant-18).

Giving Back. Another aspect of community participation that participants valued was the opportunity MY-OT-PD gave to contribute and give back to the community. This is represented when Participant-3 stated:

One of the things that I think is really great about this is that, you know we're used to being needy. With PD you have a lot of needs, but uh, I like the idea that this is a research project to do your Ph.D. and that's gonna really contribute something and we can contribute to that educational process. We're not just taking we're giving too. Others expressed gratitude for creating transactional relationships with student volunteers during the intervention. Participant-11 stated:

I think we wanna help them as much as they wanna help us too. We like having studentswe love having students. I really, in any class, anytime, I don't care if its music or exercises...anytime the students are there we are better. And I think we make the students better. 
Several participants felt like the intervention was important for all people with PD and voiced concern for spreading the information. Participant 14 said:

So he needs to know the value of the comradery and that he's not in this battle alone. We sit and laugh about it but we're doing something to try to keep it slowed down. That just needs to get out to more people, but how do you do that?

Motivation. Participants perceived the MY-OT-PD group as a source of motivation to make a positive change in daily routines, increase household safety, or participate in a social setting. Participant-11described her attendance in MY-OT-PD to be motivated by social participation when she said, “...the socialization is really important to me, just to be with a group of people."

Participant-3 perceived the MY-OT-PD group as motivation to increase household safety when he said:

You know, everybody gets a big laugh out of my porch and uh, the problem for me was getting around to it. You know what I mean? I have good intentions but getting around to it. And uh, I think that the idea that we have so many things in this notebook that we're trying to do, it really helped me to get the rubber hitting the road, you know, you've gotta really do it instead of just thinking about doing it.

\section{Theme 4: Strengthening Relationship to Self and Others}

Self-Compassion. Participants remarked that throughout MY-OT-PD they learned to foster more self-compassion. Many participants expressed learning to be gentle with themselves, as Participant-3 expressed, “There's a theme here: patience with ourselves. Being willing to cut ourselves some slack and not be disappointed with ourselves". Participants also expressed an acceptance of limitations in a compassionate way, illustrated when Participant-15 said, "I say not 
in this lifetime, don't worry about it". Of fatigue management, Participant-11 said, “Giving myself permission to rest is not something I'm good at but I'm getting better." Participants found comfort in sharing their PD symptomology with others, demonstrated when Participant-4 remarked, "And like I said I'm in such peace now. You know, finding out that this is just part of Parkinson's...it doesn't bother me now..."

Advocating. Another way in which participants perceived MY-OT-PD to be helpful was through learning to advocate for their needs with others, specifically their partners or caretakers. Many participants expressed that they "wish[ed] the caretakers would sit in on some of these classes" (Participant-9) in order for the caretakers to see things from their perspective. Participants felt empowered to communicate their feelings to partners and caretakers. For example, Participant-4 said of her partner: “...Once in a while...he'll speak and it'll be in an angry voice and I learned to say 'hey wait a minute I did not like the way that sounded, that hurts my feelings, you know, can you rephrase that'." Participant-11 also found empowerment to discuss her communication needs when she said of a conversation with her partner, "And it doesn't make me wrong and you right, it just means it's something I have to deal with. And you need to be more careful about how you say things."

\subsection{Discussion}

The aim of this study was to explore the influence of MY-OT-PD on fatigue and activity and participation measures, as well as the relationships between these constructs. Similar to previous studies, a correlation between fatigue and activity and participation scores in PD was found (Abrantes et al., 2012). This indicates that as subjective fatigue scores increased, activity and participation impairment scores also increased. This was expected as fatigue in PD has previously been connected to sleep disturbances, poor quality of life, and depression; it seems 
intuitive that experiencing those symptoms would impair one's activity and participation levels (Müller et al., 2013). Unlike other studies reporting on activity and participation in PD, this study used IMPACT-S as the assessment tool, which covers all nine ICF activity and participation domains. This is promising research because it potentially links fatigue to multiple facets of activity and participation, rather than only physical activity and communicative participation, which have been previously correlated to fatigue in PD (Garber \& Friedman, 2003; McAuliffe et al., 2017).

While quantitative changes on the MFIS were not significant after MY-OT-PD, this is unsurprising as fatigue is a non-motor symptom of PD that worsens with disease severity (Zuo et al., 2016). The increase in participants' MFIS scores could potentially be caused by the intervention increasing their awareness of fatigue. Perhaps the participants' increased MFIS scores are related to their increased activity and participation, which may have created more fatigue. Qualitative data revealed that participants learned skills for fatigue management after MY-OT-PD, including increased acceptance, awareness, and use of rest or exercise. Since fatigue is multifaceted, Nassif and Pereira (2018) stated, "fatigue management is symptomatic", and suggested that people with PD need to begin management with an awareness of fatigue, followed by education on both pharmacological and non-pharmacological treatment options (p. 148). Because MY-OT-PD included both yoga and OT, there is potential that the intervention holistically addressed the challenges of managing fatigue, through the combined physical activity of yoga with the self-management of OT.

Quantitative data revealed a statistically significant improvement in IMPACT-S scores from pre-intervention to post-intervention, quantifying the improvement in activity and participation measures after MY-OT-PD. Furthermore, qualitative data revealed outcomes 
related to all nine domains of activity and participation included in the main themes: creating mindfulness in daily activities, giving and receiving within a community, and strengthening relationship to self and others. As activity and participation are a broad concept, it is encouraging to see improvements in multiple ICF domains. There are a few interpretations that potentially explain why the improvement in activity and participation is important. For example, exercise is one facet of activity and participation, belonging to the subdomain self-care. O'Brien et al. (2016) studied the meaning of exercise participation in PD and discovered it was a way for participants to reframe their identity. They suggested that:

The presence of a chronic disease undermines the unity between body and self, and forces identity changes. People with chronic illness respond to challenges to their identity in one of two ways: adapting to it (reframing their identity)... or struggling against it (p. 478).

MY-OT-PD incorporated a multimodal, holistic intervention approach, which may have fostered the participants to adapt to or reframe their identity. Several themes that emerged from the MY-OT-PD participants are potentially related to adapting to a changing identity, specifically the subthemes "self-compassion", "fatigue acceptance", and mindfully "doing more or less". According to Yan Yan Kwok et al. (2017), "a yoga intervention is hypothesized to help a person with PD to explore one's self-boundaries, redefine their illness experience, and selftranscend to attain a sense of well-being even in the vulnerable PD trajectory" (p. 3). Yoga is a way to unite the body and self, as the word yoga translates to "union" (Woodyard, 2011). Perhaps part of the meaning participants gained from participating in MY-OT-PD was a reframing of identity. However, further research is needed to test this hypothesis. 


\section{Limitations}

A limitation of this study was the small and homogenous sample (i.e. $100 \%$ of participants were white), limiting the generalizability to the broader population with PD. The sample was a highly educated group, potentially indicating the type of people who seek out this kind of research and may already be educated on managing PD. The high education level of the group may also have increased their comprehension and utilization of information throughout MY-OT-PD.

In this study there was a large range in years since PD diagnosis ( $<1$ to 18 years). Therefore, participants were likely at different stages in disease progression. Some people were just dealing with a new diagnosis, while some have been living with PD for years and may already employ effective strategies for managing the disease. This may be a reason why the outcome measure data standard deviations were so large. A potential limitation of this study is that range in years since diagnosis was used instead of a Hoehn and Yahr disease rating scale. (Hoehn \& Yahr, 1967).

Other limitations include the sampling method being a convenience sample including people who were already attending a "yoga for PD" class held in the community before initiation of MY-OT-PD. Additionally, the first focus group included 11 people, which is relatively large for a focus group, potentially minimizing the opportunity for less vocal participants to talk. Furthermore, not all planned focus groups questions were asked due to the time limit.

\section{Future Research}

A theme that came up during the focus group analysis was the desire to have caregivers attend MY-OT-PD. This could be an area for future research: a dyadic caregiver study related to MY-OT-PD. Hinsey et al. (2018) studied the experience of caregivers in a dyadic MY-OT 
stroke intervention and discovered that, through attending the intervention, caregivers improved in the following: self-reported caregiver burden; coping strategies; positive aspects of caregiving; positive change in perspective; and increased quality time with the care receiver. While caregivers of the MY-OT-PD participants were welcome and invited to attend MY-OT-PD, none of them did. This could be in part because no emphasis or excess encouragement was made to include caregivers.

Future research could include a larger sample with a control group and a follow-up study. It could be important to include a yoga naïve group of participants. Furthermore, it would be beneficial to consistently coordinate timing of medications taken with timing assessments are administered, as timing of administered assessments in this study were based on convenience to participants. It would also be interesting to study the correlation of fatigue with more specific domains of activity and participation, to further the knowledge of how these two constructs are related.

\section{Clinical Implications}

This study has several implications for OT. First, it shows that a community program merging yoga and OT may be helpful in improving perceived fatigue management and activity and participation levels for people with PD, but further research is necessary to prove its efficacy. Additionally, this study supports a need for more community programs, including accessible yoga programming. Since people with PD may not be getting regular OT, a community program allows individual and group needs to be addressed in one setting.

This study also has implications for individual OT treatment. Occupational therapists (OTs) could use parts of MY-OT-PD (including discussions around fatigue, energy conservation, environmental factors that contribute to falls, etc.) to promote clients' awareness and 
mindfulness during daily activities. OTs should educate clients on how to seek out available community resources. If limited community resources exist, OTs are uniquely situated to empower clients to advocate for more community programs to be created, as OTs promote clients to "act in the world of reality as their own agents" (Hooper \& Wood, 2002, p.43). OTs interested in combining yoga with practice are encouraged to seek out more education on the topic, as the combination of yoga with OT practice reinforces the use of holistic treatment methods in OT (Bradshaw, 2017).

\subsection{Conclusion}

Results of this study indicate that, after MY-OT-PD, participants' activity and participation IMPACT-S scores significantly improved. Results also indicate that participants improved activity and participation in multiple ICF domains and perceived learned fatigue management. Additionally, a strong correlation was discovered between fatigue and activity and participation scores. This research furthered the understanding of using two non-pharmacological treatment options to address fatigue and activity and participation in PD. 


\section{Conflicting Interests}

The authors hold favorable opinions of yoga and OT, but tried to mitigate any bias through triangulation, peer review, and periodic, intentional reflection on biases.

\section{Research Ethics}

The Colorado State University Institutional Review Board (17-7398H) approved this study. The registration number can be found at clinicaltrials.gov "Merging Yoga and Occupational Therapy for Parkinson Disease: Phase 2” (NCT03578653).

\section{Funding}

The Lee Silverman Voice Training Global Foundation funded this study through a grant for occupational therapy students (FY17 \#137298). 


\section{Ch. 5 Clinical Implications}

People with Parkinson's disease (PD) experience impairments due to motor and nonmotor symptoms of the disease. Non-motor impairments, including fatigue, are difficult to treat, often go overlooked, and can be just as disabling as the motor impairments in PD (Nassif \& Pereira, 2018). Furthermore, these impairments can lead to a decrease in activity and participation levels for people with PD (Bryant et al., 2015). Research is in need of exploring cost-effective, non-pharmacological treatment options in PD. Both yoga and occupational therapy (OT) are examples of non-pharmacological treatment options that can be cost-effective when delivered in a group setting. This study supports a community program merging yoga and OT for fatigue management and improving activity and participation in people with PD. Additionally, this study supports a need for more community programs, including accessible yoga programming. Since people with PD may not be getting regular OT, a community program, such as adaptive yoga, allows individual and group needs to be addressed in one setting.

This study also has implications for individual OT treatment intervention. Occupational therapists (OTs) could use content from MY-OT-PD to promote clients' awareness and mindfulness during daily activities, including discussions around fatigue, energy conservation, and environmental factors that contribute to falls. OTs should educate clients on how to seek out available community resources. If limited community resources exist, OTs are uniquely situated to empower clients to advocate for more community programs to be created, as OTs promote clients to "act in the world of reality as their own agents" (Hooper \& Wood, 2002, p. 43). OTs interested in merging yoga with practice are encouraged to seek out more education on the topic, as yoga can be used for preparatory tasks, activities, and occupations if supporting a client's 
unique plan of care (Bradshaw, 2017). Furthermore, the combination of yoga with OT practice reinforces the use of holistic treatment methods in OT. 


\section{References}

Abrantes, A. M., Friedman, J. H., Brown, R. A., Strong, D. R., Desaulniers, J., Ing, E., . . Riebe, D. (2012). Physical activity and neuropsychiatric symptoms of Parkinson disease. Journal of Geriatric Psychiatry and Neurology, 25(3), 138-145.

American Occupational Therapy Association. (2014). Occupational therapy practice framework: Domain and process (3rd Ed.). American Journal of Occupational Therapy, 68 S 1- S 48. doi:http://dx.doi.org/10.5014/ajot.2014.682006

Bertram, L., \& Tanzi, R. E. (2005). The genetic epidemiology of neurodegenerative disease. The Journal of clinical investigation, 115(6), 1449-1457.

Boehm, K., Ostermann, T., Milazzo, S., \& Büssing, A. (2012). Effects of yoga interventions on fatigue: a meta-analysis. Evidence-Based Complementary Alternative Medicine, 2012.

Bradshaw, M. (2017). Occupational Therapy and Complementary Health Approaches and Integrative Health. American Journal of Occupational Therapy, 71, 1-6.

Bryant, M., Rintala, D., Hou, J., \& Protas, E. (2015). Relationship of falls and fear of falling to activity limitations and physical inactivity in Parkinson's disease. European Neurology, 23(2), 187-193.

Bryant, M., Rintala, D. H., Hou, J., Rivas, S., Fernandez, A., Lai, E., \& Protas, E. (2012). The relation of falls to fatigue, depression and daytime sleepiness in Parkinson's disease. Journal of Neurology, 67(6), 326-330.

Dahlke, A. R., Curtis, L. M., Federman, A. D., \& Wolf, M. S. (2014). The Mini Mental Status Exam as a Surrogate Measure of Health Literacy. Journal of General Internal Medicine, 29(4), 615-620. doi:10.1007/s11606-013-2712-x

Davie, C. A. (2008). A review of Parkinson's disease. British Medical Bulletin, 86(1), 109-127. 
Dixon, L., Duncan, D., Johnson, P., Kirkby, L., O'Connell, H., Taylor, H., \& Deane, K. (2007). Occupational therapy for patients with Parkinson's disease. Cochrane Database of Systematic Reviews(3), CD002813-CD002813.

Elbers, R. G., Verhoef, J., van Wegen, E. E., Berendse, H. W., \& Kwakkel, G. (2015). Interventions for fatigue in Parkinson's disease. Cochrane Database of Systematic Reviews(10).

Foster, E. R., Bedekar, M., \& Tickle-Degnen, L. (2014). Systematic review of the effectiveness of occupational therapy-related interventions for people with Parkinson's disease. American Journal of Occupational Therapy, 68(1), 39-49.

Garber, C. E., \& Friedman, J. H. (2003). Effects of fatigue on physical activity and function in patients with Parkinson's disease. Journal of Neurology, 60(7), 1119-1124.

Gauthier, L., Dalziel, S., \& Gauthier, S. (1987). The benefits of group occupational therapy for patients with Parkinson's disease. American Journal of Occupational Therapy, 41(6), $360-365$.

Gazibara, T., Pekmezovic, T., Kisic Tepavcevic, D., Tomic, A., Stankovic, I., Kostic, V. S., \& Svetel, M. (2015). Fall frequency and risk factors in patients with Parkinson's disease in Belgrade, Serbia: A cross-sectional study. Geriatrics Gerontology International, 15(4), 472-480.

Hawkins, B. L., Van Puymbroeck, M., Walter, A., Sharp, J., Woshkolup, K., Urrea-Mendoza, E., ... Schmid, A. A. (2018). Perceived activities and participation outcomes of a yoga intervention for individuals with Parkinson's disease: a mixed methods study. International Journal of Yoga Therapy, 28(1), 51-61. 
Hinsey, K. M., Atler, K. E., Fruhauf, C. A., Boster, R. A., Van Puymbroeck, M., \& Schmid, A. A. (2018 ). A Multi-modal Intervention after Stroke: The Caregiver Experience OBM Integrative and Complementary Medicine, 3(2). doi:doi:10.21926/obm.icm.1802010

Hoehn, M. M., \& Yahr, M. D. (1967). Parkinsonism: onset, progression and mortality. Journal of Neurology, 17(5), 427-442.

Hooper, B., \& Wood, W. (2002). Pragmatism and structuralism in occupational therapy: The long conversation. American Journal of Occupational Therapy, 56(1), 40-50.

Kader, M., Iwarsson, S., Odin, P., \& Nilsson, M. H. (2016). Fall-related activity avoidance in relation to a history of falls or near falls, fear of falling and disease severity in people with Parkinson's disease. BMC Neurology, 16(1), 84.

Kluger, B. M., Garimella, S., \& Garvan, C. (2017). Minimal clinically important difference of the Modified Fatigue Impact Scale in Parkinson's disease. Parkinsonism Related Disorders, 43, 101-104.

Kluger, B. M., Herlofson, K., Chou, K. L., Lou, J. S., Goetz, C. G., Lang, A. E., . . Friedman, J. (2016). Parkinson's disease-related fatigue: A case definition and recommendations for clinical research. Journal of Movement Disorders, 31(5), 625-631.

Kluger, B. M., Krupp, L. B., \& Enoka, R. M. (2013). Fatigue and fatigability in neurologic illnesses: proposal for a unified taxonomy. Journal of Neurology, 80(4), 409-416.

Kostić, V. S., Tomić, A., \& Ječmenica-Lukić, M. (2016). The pathophysiology of fatigue in Parkinson's disease and its pragmatic management. Movement Disorders Clinical Practice, 3(4), 323-330.

Lee, A., \& Gilbert, R. M. (2016). Epidemiology of Parkinson disease. Neurologic Clinics, 34(4), 955-965. 
Lindholm, B., Hagell, P., Hansson, O., \& Nilsson, M. H. (2014). Factors associated with fear of falling in people with Parkinson's disease. BMC Neurology, 14(1), 19.

McAuliffe, M. J., Baylor, C. R., \& Yorkston, K. M. (2017). Variables associated with communicative participation in Parkinson's disease and its relationship to measures of health-related quality-of-life. International Journal of Speech-Language Pathology 19(4), 407-417.

Miller, K. K., Combs, S. A., Van Puymbroeck, M., Altenburger, P. A., Kean, J., Dierks, T. A., \& Schmid, A. A. (2013). Fatigue and pain: relationships with physical performance and patient beliefs after stroke. Topics in Stroke Rehabilitation, 20(4), 347-355.

Müller, B., Assmus, J., Herlofson, K., Larsen, J. P., \& Tysnes, O.-B. (2013). Importance of motor vs. non-motor symptoms for health-related quality of life in early Parkinson's disease. Journal of Parkinsonism and Related Disorders, 19(11), 1027-1032.

Nassif, D. V., \& Pereira, J. S. (2018). Fatigue in Parkinson's disease: concepts and clinical approach. Psychogeriatrics, 18(2), 143-150.

Nayak, N. N., \& Shankar, K. (2004). Yoga: a therapeutic approach. Physical Medicine Rehabilitation Clinics, 15(4), 783-798.

Ni, M., Mooney, K., \& Signorile, J. F. (2016). Controlled pilot study of the effects of power yoga in Parkinson's disease. Complementary Therapies in Medicine, 25, 126-131.

Nijrolder, I., van der Windt, D. A., \& van der Horst, H. E. (2008). Prognosis of fatigue and functioning in primary care: a 1-year follow-up study. The Annals of Family Medicine, 6(6), 519-527.

Nutt, J. G., \& Wooten, G. F. (2005). Diagnosis and initial management of Parkinson's disease. New England Journal of Medicine, 353(10), 1021-1027. 
O’Brien, C., Clemson, L., \& Canning, C. G. (2016). Multiple factors, including non-motor impairments, influence decision making with regard to exercise participation in Parkinson's disease: a qualitative enquiry. Disability Rehabilitation, 38(5), 472-481.

Oken, B. S., Kishiyama, S., Zajdel, D., Bourdette, D., Carlsen, J., Haas, M., . . Mass, M. (2004). Randomized controlled trial of yoga and exercise in multiple sclerosis. Journal of Neurology, 62(11), 2058-2064.

Ongre, S., Larsen, J., Tysnes, O., \& Herlofson, K. (2017). Fatigue in early Parkinson's disease: the Norwegian ParkWest study. European Journal of Neurology, 24(1), 105-111.

Pickering, R. M., Grimbergen, Y. A., Rigney, U., Ashburn, A., Mazibrada, G., Wood, B., . . . Bloem, B. R. (2007). A meta-analysis of six prospective studies of falling in Parkinson's disease. Journal of Movement Disorders, 22(13), 1892-1900.

Post, M. W., de Witte, L. P., Reichrath, E., Verdonschot, M. M., Wijlhuizen, G. J., \& Perenboom, R. J. (2008). Development and validation of IMPACT-S, an ICF-based questionnaire to measure activities and participation. Journal of Rehabilitation Medicine, $40(8), 620-627$.

Rochester, L., Hetherington, V., Jones, D., Nieuwboer, A., Willems, A. M., Kwakkel, G., \& Van Wegen, E. (2004). Attending to the task: interference effects of functional tasks on walking in Parkinson's disease and the roles of cognition, depression, fatigue, and balance. Archives of Physical Medicine and Rehabilitation, 85(10), 1578-1585.

Rochester, L., Jones, D., Hetherington, V., Nieuwboer, A., Willems, A.-M., Kwakkel, G., \& Wegen, E. V. (2006). Gait and gait-related activities and fatigue in Parkinson's disease: what is the relationship? Journal of Disability and Rehabilitation 28(22), 1365-1371. 
Schiehser, D. M., Ayers, C. R., Liu, L., Lessig, S., Song, D. S., \& Filoteo, J. V. (2013). Validation of the modified fatigue impact scale in Parkinson's disease. Parkinsonism Related Disorders, 19(3), 335-338.

Schmid, A. A., Van Puymbroeck, M., Portz, J. D., Atler, K. E., \& Fruhauf, C. A. (2016). Merging Yoga and Occupational Therapy (MY-OT): A feasibility and pilot study. Complementary Therapies in Medicine, 28, 44-49.

Schoonenboom, J., \& Johnson, R. B. J. K. K. Z. f. S. u. S. (2017). How to construct a mixed methods research design. 69(2), 107-131.

Sharma, N. K., Robbins, K., Wagner, K., \& Colgrove, Y. M. (2015). A randomized controlled pilot study of the therapeutic effects of yoga in people with Parkinson's disease. International Journal of Yoga, 8(1), 74.

Siciliano, M., Trojano, L., De Micco, R., De Mase, A., Garramone, F., Russo, A., . . Tessitore, A. (2017). Motor, behavioural, and cognitive correlates of fatigue in early, de novo Parkinson disease patients. Parkinsonism Related Disorders, 45, 63-68.

Spears, C. (2018). Dopamine Agonists Retrieved from http://www.parkinson.org/UnderstandingParkinsons/Treatment/Prescription-Medications/Dopamine-Agonists

Sturkenboom, I. H., Graff, M. J., Borm, G. F., Veenhuizen, Y., Bloem, B. R., Munneke, M., \& Nijhuis-van der Sanden, M. W. (2013). The impact of occupational therapy in Parkinson's disease: a randomized controlled feasibility study. Journal of Clinical Rehabilitation, 27(2), 99-112.

Swink, L.A., Atler, K.E., Klinedinst, T.C., Fling, B.W., Fruhauf, C.A., Schmid, A.A. (2019, April). Meeting the needs of people with Parkinson disease through the adaptation of a fall risk program: Merging Yoga and Occupational Therapy for Parkinson Disease. 
Poster presentation at the American Occupational Therapy Association Annual Conference, New Orleans, LA.

Van der Zee, C. H., Priesterbach, A. R., van der Dussen, L., Kap, A., Schepers, V. P., VisserMeily, J., \& Post, M. W. (2010). Reproducibility of three self-report participation measures: The ICF Measure of Participation and Activities Screener, the Participation Scale, and the Utrecht Scale for Evaluation of Rehabilitation-Participation. Journal of Rehabilitation Medicine, 42(8), 752-757.

Van Hilten, J., Weggeman, M., Van der Velde, E., Kerkhof, G., Van Dijk, J., \& Roos, R. (1993). Sleep, excessive daytime sleepiness and fatigue in Parkinson's disease. Journal of Neural Transmission-Parkinson's Disease Dementia Section, 5(3), 235-244.

Van Puymbroeck, M., Walter, A., Hawkins, B. L., Sharp, J. L., Woschkolup, K., UrreaMendoza, E., .. . Schmid, A. A. (2018). Functional Improvements in Parkinson's Disease Following a Randomized Trial of Yoga. Evidence-Based Complementary Alternative Medicine, 2018.

Walter, A. A., Adams, E. V., Van Puymbroeck, M., Crowe, B. M., Urrea-Mendoza, E., Hawkins, B. L., .. . Schmid, A. A. (2019). Changes in Nonmotor Symptoms Following an 8-Week Yoga Intervention for People with Parkinson's Disease. International Journal of Yoga Therapy.

Watkins, M. P., \& Portney, L. (2009). Foundations of clinical research: applications to practice: Pearson/Prentice Hall Upper Saddle River, NJ.

WHO, W. H. O. (2002). Towards a common language for functioning, disability and health: ICF. Geneva, Switzerland: World Health Organization. In: Retrieved 06/20/2012 from http://www. who. int/classifications/icf/beginners/bg. pdf. 
Winward, C., Sackley, C., Meek, C., Izadi, H., Barker, K., Wade, D., \& Dawes, H. (2012). Weekly exercise does not improve fatigue levels in Parkinson's disease. Movement Disorders, 27(1), 143-146.

Wood, B., Bilclough, J., Bowron, A., Walker, R., \& Psychiatry. (2002). Incidence and prediction of falls in Parkinson's disease: a prospective multidisciplinary study. Journal of Neurology, Neurosurgery, 72(6), 721-725.

Woodyard, C. (2011). Exploring the therapeutic effects of yoga and its ability to increase quality of life. International Journal of Yoga, 4(2), 49.

Yan Yan Kwok, J., Cheuk Yin Kwan, J., Auyeung, M., Chung Tong Mok, V., \& Yue Lai Chan, H. (2017). The effects of yoga versus stretching and resistance training exercises on psychological distress for people with mildto-moderate Parkinson's disease: study prxotocol for a randomized controlled trial. Trials, 18.

Zuo, L.-J., Yu, S.-Y., Wang, F., Hu, Y., Piao, Y.-S., Du, Y., . . Wang, Y.-J. (2016). Parkinson's Disease with Fatigue: Clinical Characteristics and Potential Mechanisms Relevant to $\alpha$ Synuclein Oligomer. Journal of Clinical Neurology, 12(2), 172-180. 